$10 / 18.94850$
$10^{1}$
SANDIA REPORT

SAND94-1772 • UC-706

Unlimited Release

Printed September 1994

\title{
Evaluation of Mil-F-28861 Filters and Suppliers
}

\author{
Steven E. Grieco
}

\section{Prepared by}

Sandia National Laboratorles

Albuquerque, New Mexico 87185 and Livermore, Callfornia 94550 for the United States Department of Energy under Contract DE-AC04-94AL85000

Approved for public release; distribution is unlimited.
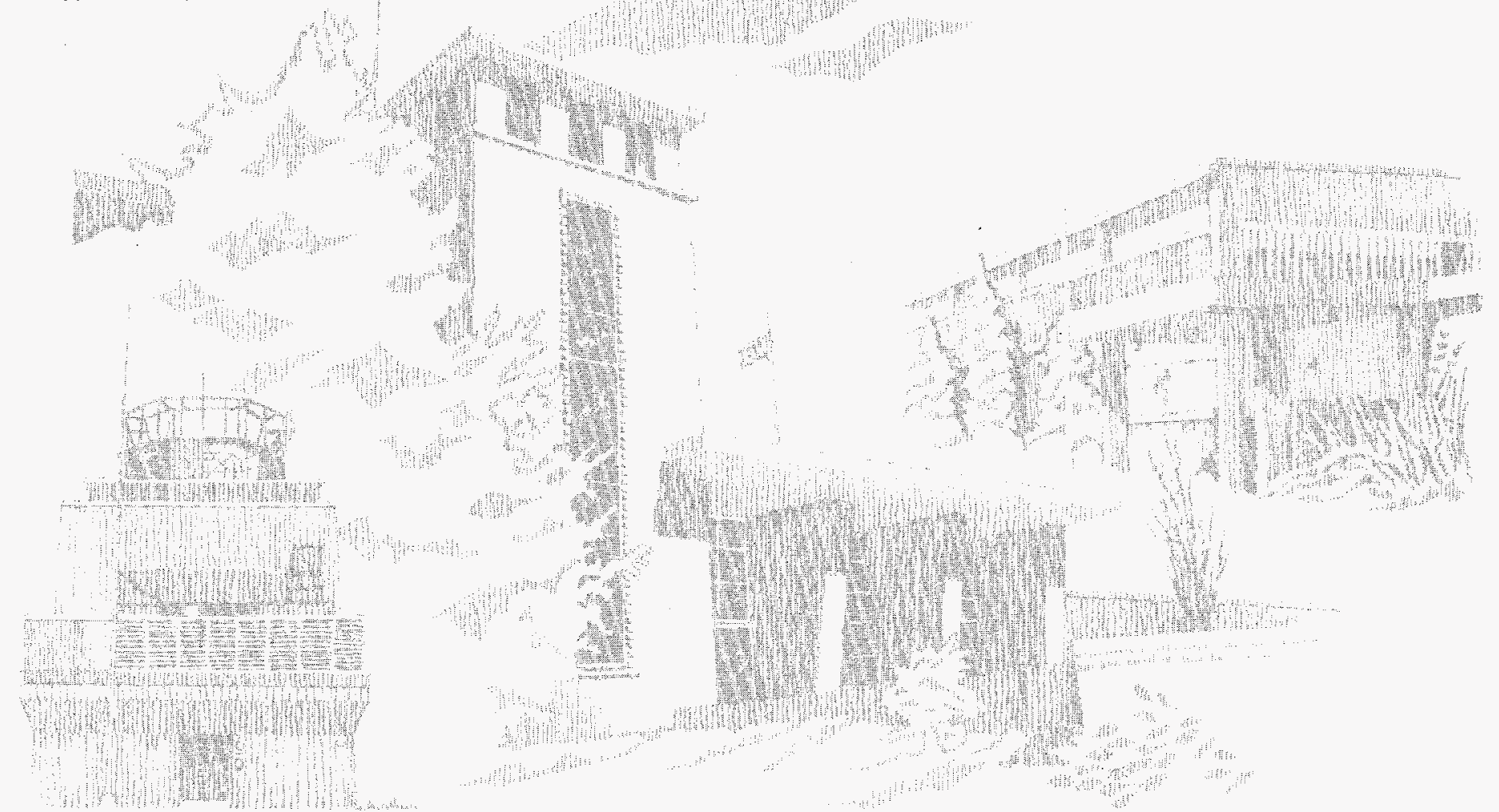
Issued by Sandia National Laboratories, operated for the United States Department of Energy by Sandia Corporation.

NOTICE: This report was prepared as an account of work sponsored by an agency of the United States Government. Neither the United States Government nor any agency thereof, nor any of their employees, nor any of their contractors, subcontractors, or their employees, makes any warranty, express or implied, or assumes any legal liability or responsibility for the accuracy, completeness, or usefulness of any information, apparatus, product, or process disclosed, or represents that its use would not infringe privately owned rights. Reference herein to any specific commercial product, process, or service by trade name, trademark, manufacturer, or otherwise, does not necessarily constitute or imply its endorsement, recommendation, or favoring by the -United States Government, any agency thereof or any of their contractors or subcontractors. The views and opinions expressed herein do not necessarily state or reflect those of the United States Government, any agency thereef or any of their contractors.

Printed in the United States of American. This report has been reproduced directly from the best available copy.

Available to DOE and DOE contractors from

Office of Scientific and Technical Information

PO Box 62

Oak Ridge, TN 37831

Prices available from (615) 576-8401, FTS 626-8401

Available to the public from

National Technical Information Service

US Department of Commerce

5285 Port Royal RD

Springfield, VA 22161

NTIS price codes

Printed copy: A03

Microfiche copy: A06 


\section{DISCLAIMER}

Portions of this document may be illegible in electronic image products. Images are produced from the best available original document. 
SAND94-1772 - Revised

Unlimited Release

Printed March 1995

Distribution

Category UC-706

\title{
Evaluation of Mil-F-28861 Filters and Suppliers
}

\author{
Steven E. Grieco \\ Component Information and Management Department \\ Sandia National Laboratories \\ Albuquerque, New Mexico 87185
}

\begin{abstract}
Over the last 20 years, a family of lowpass filters has been developed to eliminate electromagnetic interference from power and signal lines in weapon systems. Since its inception, Sprague Electric in North Adams, Massachusetts, has produced this family of components on a line dedicated solely to these devices. Although at least seven other companies produce similar filters, suppliers are unwilling to build small quantities of components in a manner that is incompatible with their standard methods and equipment. The ability to fabricate products in small quantities on an occasional basis is an important factor in component development, and compatibility with commercially available devices enhances that ability. The Mil-F-28861/5 specifications, developed by the Defense Electronic Parts Supply Center, describe filters similar to those of the MC family. This report documents the evaluation of Mil-F-28861/5 filters acquired from the eight suppliers and serves as a basis for further development of specifications and suppliers.
\end{abstract}





\section{Contents}

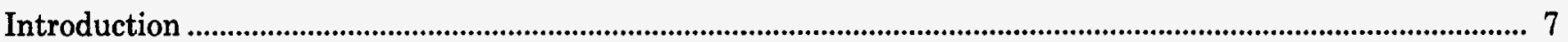

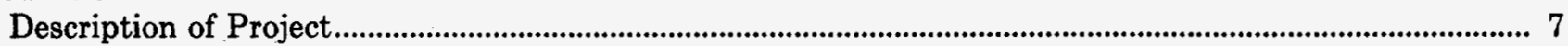

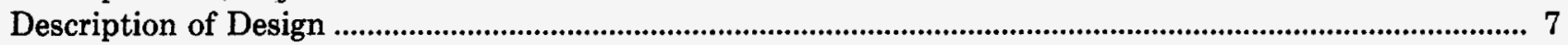

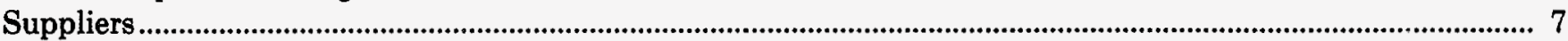

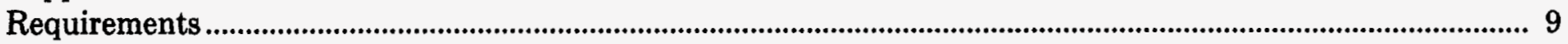

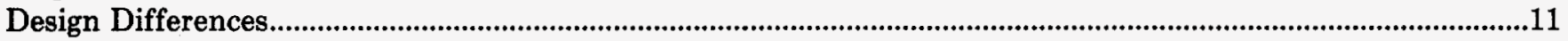

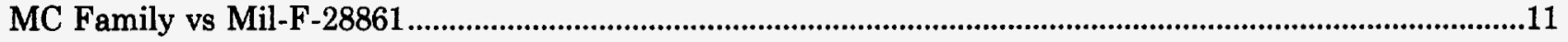

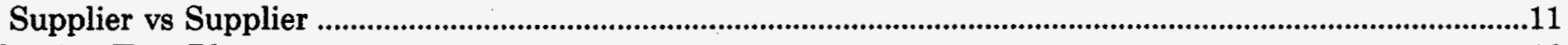

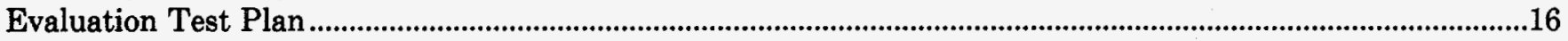

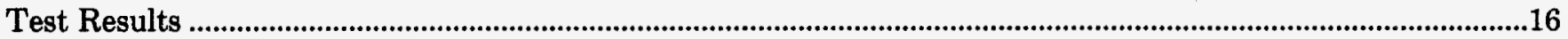

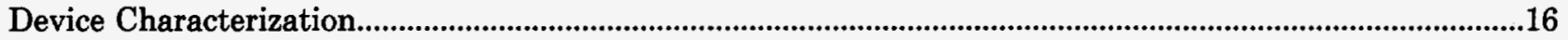

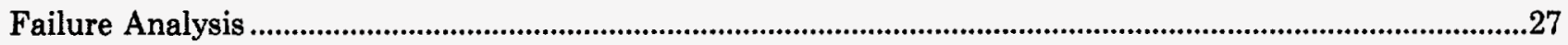

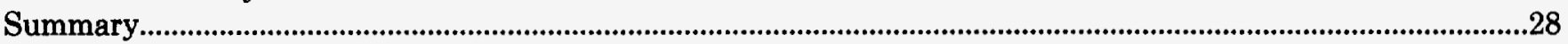

\section{Figures}

1 Family of Lowpass Filters.

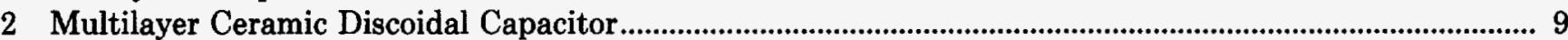

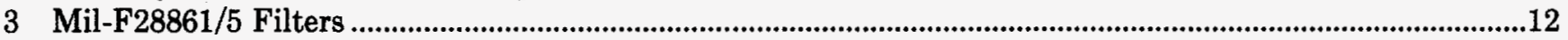

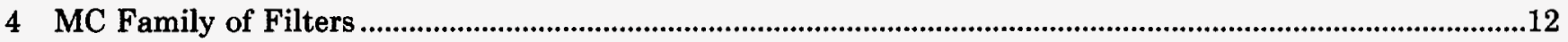

5 Average Inductance $(\mathrm{uH})$ for MC2871, MC2867, and MC2944......................................................................13

6 Average Capacitance (uF) for MC2871, MC2867, and MC2944....................................................................13

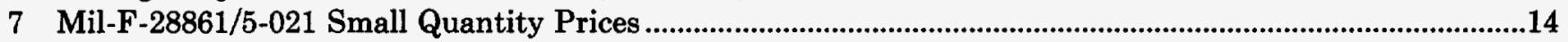

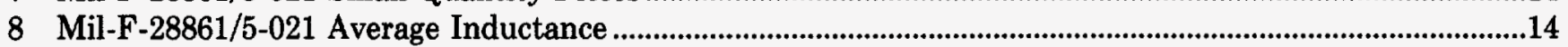

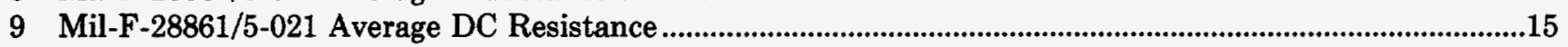

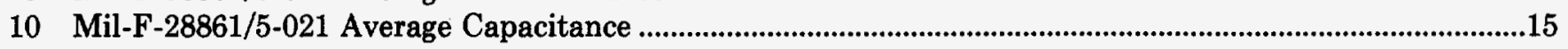

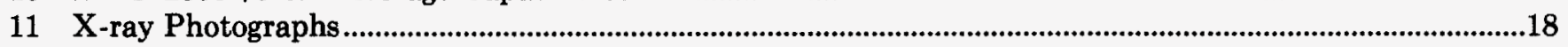

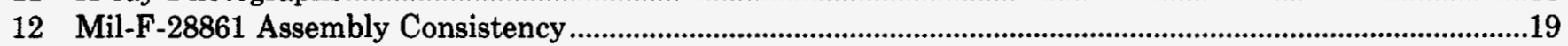

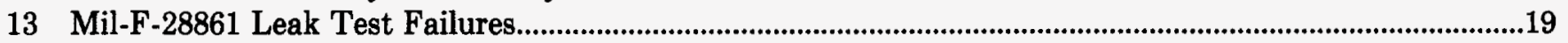

14 Mil-F-28861 Insulation Resistance at Room Temperature .................................................................................20

15 Room Temperature Insulation Resistance in Gohm $\times$ ufd ...........................................................................20

16 Mil-F-28861/5-021 Inductance Change with 2-Ampere Load..........................................................................21

17 Attenuation Performance vs MC2871 Specification ...........................................................................................22

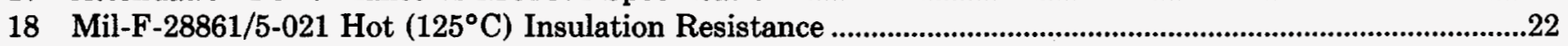

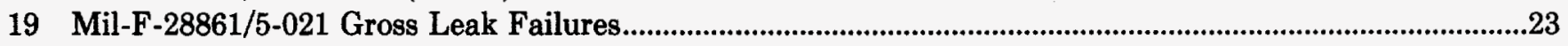

20 Mil-F-28861/5-021 Capacitance Sigma Before and After Cycling ....................................................................24

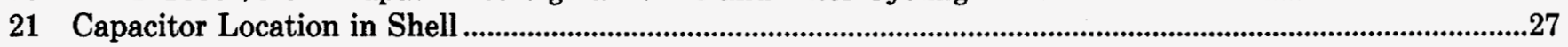




\section{Tables}

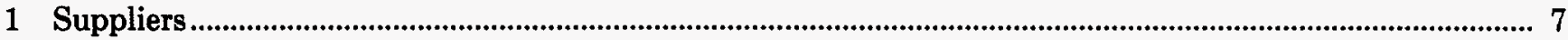

2 Mil-F-28861 QPL Status as of March 1992

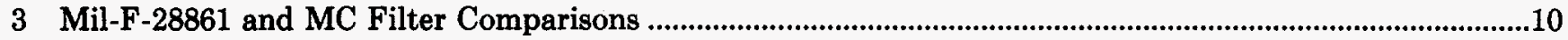

4 Comparison of Electrical Characteristics Among Suppliers ...........................................................................14

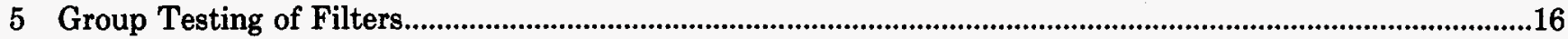

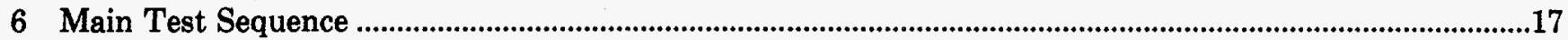

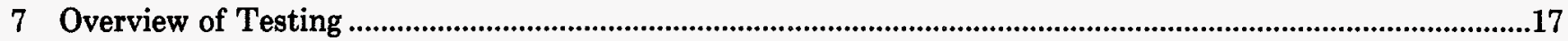

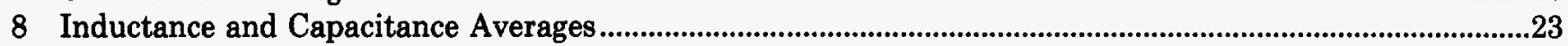

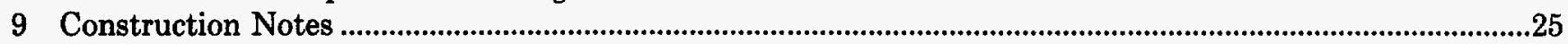

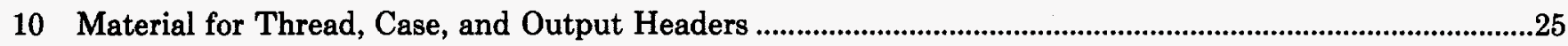

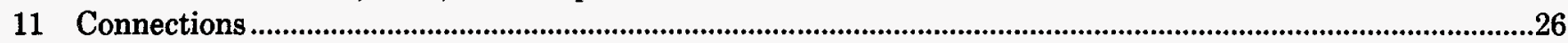

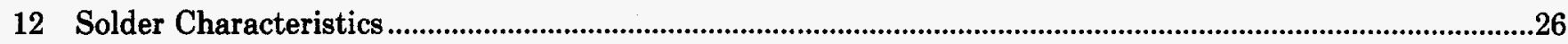

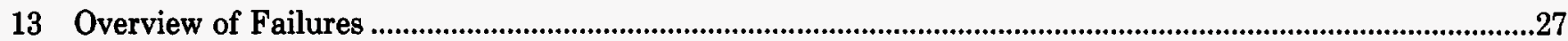




\section{Evaluation of Mil-F-28861 Filters and Suppliers}

\section{Introduction}

\section{Description of Project}

Over the last 20 years, a family of lowpass filters has been developed to eliminate electromagnetic interference (EMI) from power and signal lines in weapon systems. Since its inception, Sprague Electric in North Adams, Massachusetts, has produced this family of components on a line dedicated solely to these devices. As an MC class of components, drawings and specifications developed at Sandia National Laboratories and at Allied Signal, Kansas City, governed all aspects of production including parts design, assembly flow, assembly processes, and testing. When production rates were reduced in 1990, there was insufficient volume to maintain this dedicated line. Although at least seven other companies produce similar filters, suppliers are unwilling to build small quantities of components in a manner that is incompatible with their standard methods and equipment.

The ability to fabricate products in small quantities on an occasional basis is an important factor in component development, and compatibility with commercially available devices enhances that ability. The Mil-F-28861/5 specifications, developed by the Defense Electronic Parts Supply Center (DESC), are similar to those of the MC family. If filters manufactured to the Mil-F-28861/5 specifications could meet or nearly meet the performance requirements of the MC family, it would be possible to develop designs based on the Mil-F-28861/5 series for future programs. This report documents the evaluation of MilF-28861/5 filters acquired from the eight suppliers and serves as a basis for further development of specifications and suppliers.

\section{Description of Design}

The family of lowpass filters being considered consists of the MC2867, MC2868, MC2871, and MC2944 (Figure 1). Each filter is a Pi network with a series inductor between two shunt capacitors. The inductor is a coil of wire wound around one or more powdered iron toroidal cores. The capacitors are multilayer ceramic discoidal types having alternating layers of metalization connected to either the inside or outside diameter of the donut-shaped device (Figure 2). Each end of the coil wire is soldered to the inside diameter of one discoidal capacitor and continues to one of the terminal lugs, which provide a means of attachment for the eventual user. The outside diameter metalization of the discoidal capacitors is soldered to the inside of the tubular metal shell. The shell has a threaded adapter at one end that serves as a means for mounting to a bulkhead and as the electrical ground when the bulkhead is properly installed. Connected in this manner, the series path is from one terminal lug to the other, passing through the coil located between them. The shunt paths are the two capacitors to the grounded shell. The assembly is hermetic and each terminal is part of a glasssealed header.

\section{Suppliers}

Table 1 lists the name and location of all the suppliers included in our study. We included all companies known to produce these kinds of EMI filters, regardless of their qualified parts list (QPL) (DESC Qualified Supplier List) status.

Table 1. Suppliers

Supplier Location

AVX Microtek Ceramic Devices Inc. Murata Erie RFI Sierra Aerospace San Fernando Electric Spectrum Control Sprague Electric
Sun Valley, California San Diego, California Trenton, Ontario, Canada Long Island, New York Carson City, Nevada San Fernando, California Erie, Pennsylvania North Adams, Massachusetts 


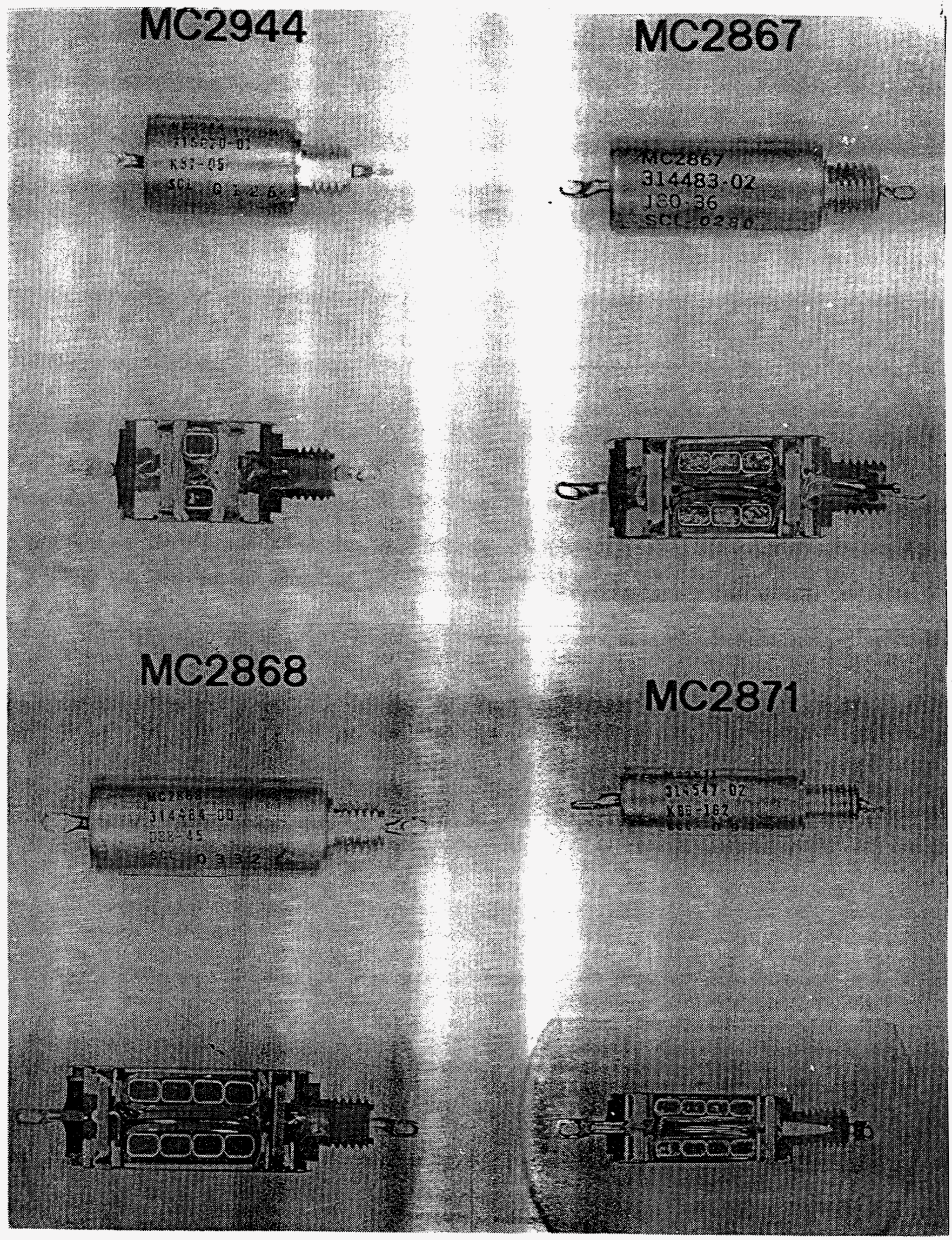

Figure 1. Family of Lowpass Filters. 


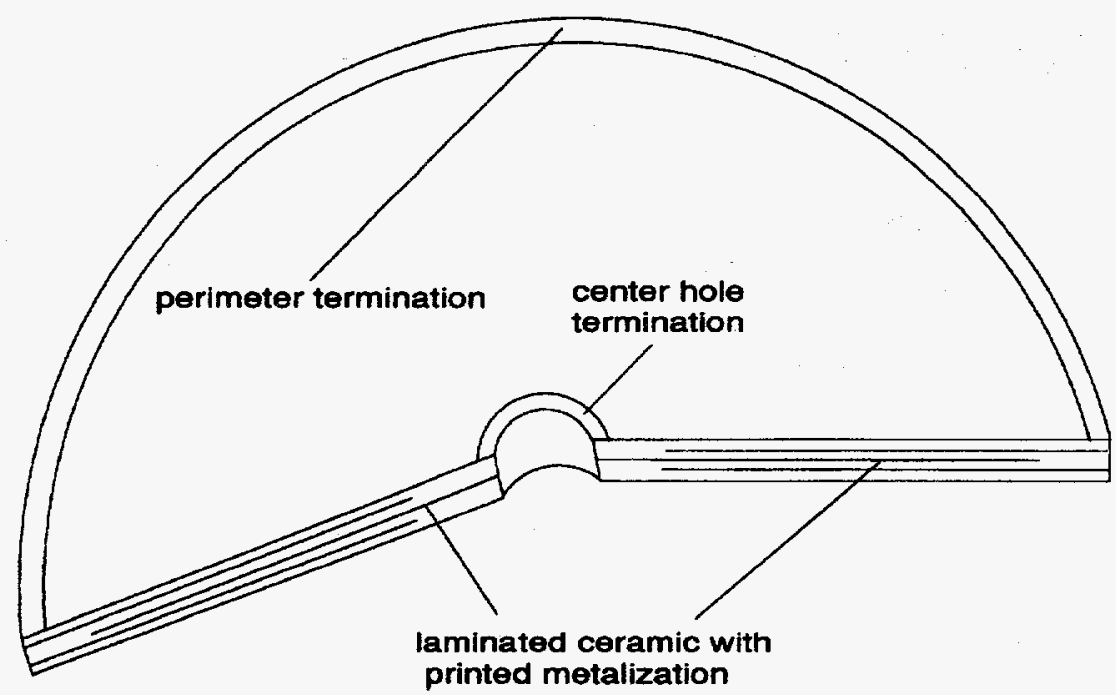

Figure 2. Multilayer Ceramic Discoidal Capacitor.

AVX Microtek originated as U.S. Capacitor and, as U.S. Microtek, was part of Unitrode for a period of time ending in 1990. AVX Corporation is part of the Kyocera Group of Companies. In April 1992, Murata Erie was sold to Spectrum Control and the Trenton, Ontario, plant was closed. Some months earlier, San Fernando Electric (SFE) went out of business. In the first quarter of 1992, Maxwell Labs bought Sierra Aerospace, and Vishay Corporation acquired Sprague Electric. All of the filters used in this evaluation were acquired before these developments occurred, and companies no longer in business will be referred to in the present tense.

AVX has ceased making ceramic capacitors at the Sun Valley location, and now buys or transfers them from the AVX facility in Conway, South Carolina. Sprague Electric also uses AVX as the source for their capacitors after closing their Wichita Falls, Texas, ceramic capacitor plant in 1990. Spectrum Control makes their own capacitors at a plant in New Orleans, Louisiana, that was once owned by San Fernando Electric. Murata, Ceramic Devices Inc. (CDI), and Sierra Aerospace all make their capacitors at their filter manufacturing site. RFI buys capacitors from
AVX, Sierra, and a nonfilter supplier, but is working on the capability to build their own.

All of the suppliers are willing to allow source inspection for lot acceptance, use customer-supplied test equipment, produce similar but nonstandard filters, and maintain baseline documentation and processes.

Table 2 shows the QPL status as of March 1992. This information comes from the DESC document QPL-28861-19. This table is provided for reference only and was not used in the evaluation in any way. The slash 5 series of filters is the closest to our MC group of devices.

\section{Requirements}

A side-by-side comparison between Mil-F-28861 and MC filters is provided in Table 3 . It shows that the MC specifications have a more difficult mechanical shock requirement while the Mil-F-28861 has a higher level of sinusoidal vibration stress and longer aging requirements but no random vibration. The Mil-F-28861 allows more design flexibility in terms of inductance and capacitance. 
Table 2. Mil-F-28861 QPL Status as of March 1992.

\begin{tabular}{clrrrrr} 
& & \multicolumn{5}{c}{ Dash Numbers Qualified for: } \\
\cline { 3 - 7 } Slash Sheet & Package Type & AVX & CDI & Sierra & Spectrum & Sprague \\
\hline 1 & Broadband Bulkhead & 12 & 8 & 8 & 20 & 20 \\
2 & Broadband Bulkhead & 24 & 24 & 0 & 0 & 24 \\
3 & Broadband Bulkhead & 0 & 0 & 0 & 0 & 36 \\
4 & Broadband Bulkhead & 36 & 0 & 0 & 0 & 36 \\
5 & Broadband Bulkhead & 24 & 0 & 24 & 0 & 24 \\
6 & Bolt & 0 & 0 & 4 & 0 & 0 \\
12 & Eyelet & 0 & 0 & 36 & 0 & 0 \\
& & & & & & \\
& Total & 96 & 32 & 72 & 20 & 140 \\
& Total Types & 4 & 2 & 4 & 1 & 5 \\
\hline \hline
\end{tabular}

Table 3. Mil-F-28861 and MC Filter Comparisons.

Item

Insulation Resistance (IR)

IR@+125ㄷ

$\mathrm{X}$-ray

Solderability

Dissipation Factor

Capacitance

Inductance

Dielectric Strength (DC)

Dielectric Strength (Transient)

Hi-Power Attenuation

Thermal Shock

Swept Vibration I

Swept Vibration II

Random Vibration

Mechanical Shock I

Mechanical Shock II

Aging
MC Filter

$1000 \mathrm{M} \Omega \mathrm{min}$.

$500 \mathrm{M} \Omega \min$.

$100 \%, 2$ planes

$25 \mathrm{pcs} / \mathrm{lot}$

$2.5 \%$ max. (capacitors only)

Range

Range

DC level, 120 sec.

500 Vpeak, $15 \mu \mathrm{sec}$

Max. v out, 800 ma in

5 cycles, $+125,-55^{\circ} \mathrm{C}$

$10 \mathrm{~g}, 20-2 \mathrm{kHz}$,

2 cycles $\times 30$ minutes $\times 2$ axes

0.25 inch, $10-20 \mathrm{~Hz}$,

2 cycles $\times 30$ minutes $\times 2$ axes

$0.03 \mathrm{~g}^{2} / \mathrm{Hz}, 20-2 \mathrm{kHz}$,

3 minutes $\times 2$ axes

$275 \mathrm{~g}$, triangle, $3 \mathrm{msec}$

$100 \mathrm{~g}$, haversine, $11 \mathrm{msec}$

$400 \mathrm{~V}, 48 \mathrm{hr},+125 \mathrm{C}$,

(capacitors only)
Mil-F-28861

$1000 \mathrm{M} \Omega \min$.

$100 \mathrm{M} \Omega \mathrm{min}$.

$100 \%, 2$ planes

$5 \mathrm{pcs} / \mathrm{lot}$

$3 \% \max$.

minimum

-

DC level, 5-60 sec.

$-$

$-$

5 Cycles, $+125,-55^{\circ} \mathrm{C}$

$50 \mathrm{~g}, 20-3 \mathrm{kHz}, 12$ cycles

$\times 20$ minutes $\times 3$ axes

-

$100 \mathrm{~g}$, sawtooth, $6 \mathrm{msec}$

$400 \mathrm{~V}, 164 \mathrm{hr},+125^{\circ} \mathrm{C}$ 


\section{Design Differences}

\section{Family vs Mil-F-28861}

The Mil-F-28861/5 family is a group of devices with capacitors designed for a dielectric withstanding rating of 200 volts. It includes four different circuit configurations: feedthrough capacitors (shunt capacitor), L-sections (series inductance and a shunt capacitor), T-section (shunt capacitor between two series inductors), and $\mathrm{Pi}$-sections (series inductor between two shunt capacitors). The dash numbers designate the circuit configuration and current rating. The -021 (dash 21) is a Pi filter rated for 3 amperes DC similar to our MC2871; the -024 is similar to our MC2867, MC2868, and MC2944 and is rated for 5 amperes DC. All of these Mil-Standard filters have the mechanical dimensions shown in Figure 3.

This outline in Figure 3 can be compared to the dimensions of the MC family of filters shown in Figure 4.

One of the factors driving the differences in dimensions is the coil design. The graph in Figure 5 shows that for the MC2867 and MC2871, the comparable Mil-Standard filter uses less inductance and more capacitance. In both cases, the inductance of the Mil-Standard filters is about the highest achievable in the allowable package and is limited by the wire gauge, which is driven by the current rating of the device. The reason for the larger diameter in the
MC2944 is not clear, but downstream circuits require the filter to have a low level of inductance. The inductance of the Mil-F-28861/5-024 is higher, but should be acceptable.

All designs use wound toroidal coils for inductive elements and multilayer ceramic discoidal capacitors. All Mil-Standard coils have a single toroid core while some MC filter coils have multiple cores: MC2867 (3 cores), MC2868 (4 cores), and MC2871 (4 cores). In all of these cases, the MC coil cores are put side-by-side and wound as a single core. The capacitance of Mil-Standard filters is specified as a minimum of .3 ufd while the capacitance of the MC Filters is specified to be in a narrow range. The values are compared in the graph shown in Figure 6.

The MC filters use no potting material to constrain the coils while most Mil-Standard filters do. However, the Mil-Standard designs are driven by supplier preference or engineering judgment rather than by specification. Sprague and SFE are the only two suppliers that do not use potting in their MilStandard filters while MC filters, by specification, do not.

\section{Supplier vs Supplier}

This section compares designs among suppliers; Figure 7 is included for reference purposes.

The basic electrical characteristics are summarized in Table 4 with details provided in Figures 8 through 10 as noted in the table. 


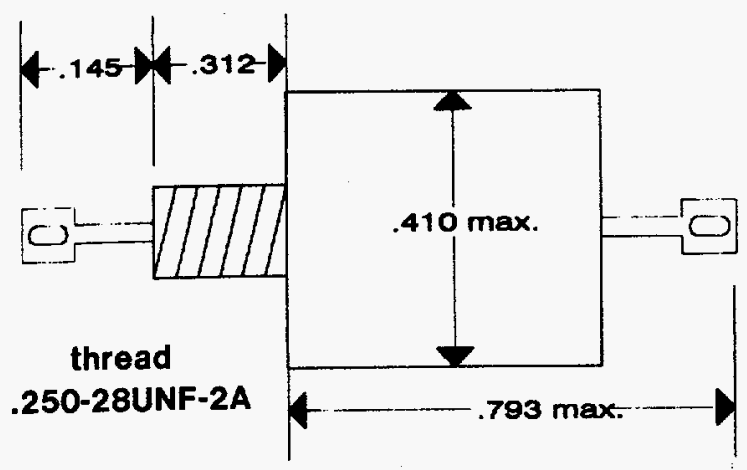

Figure 3. Mil-F-28861/5 Filters.

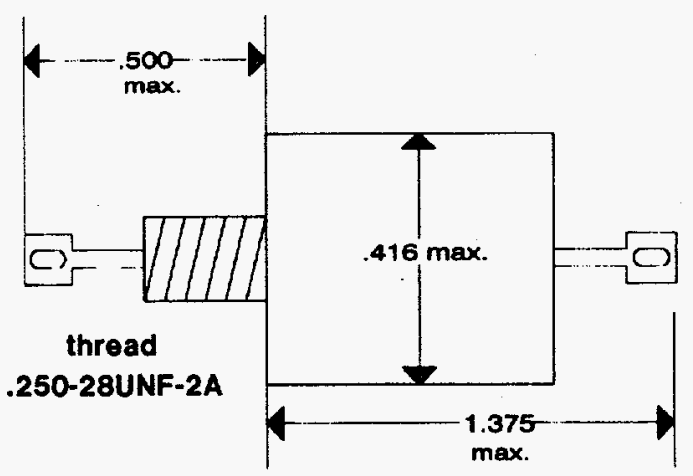

MC2871

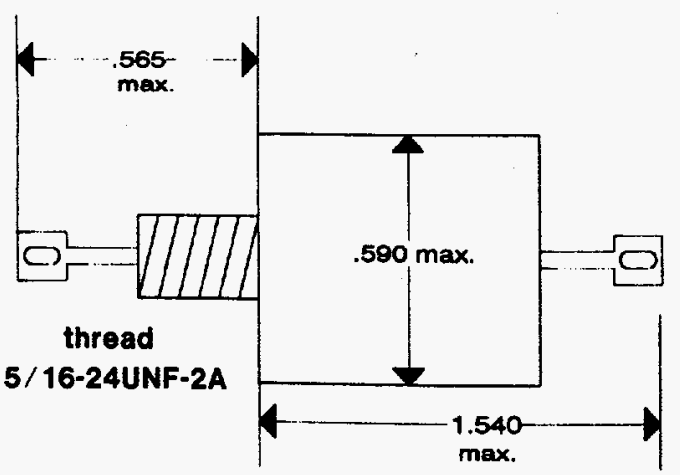

MC2867

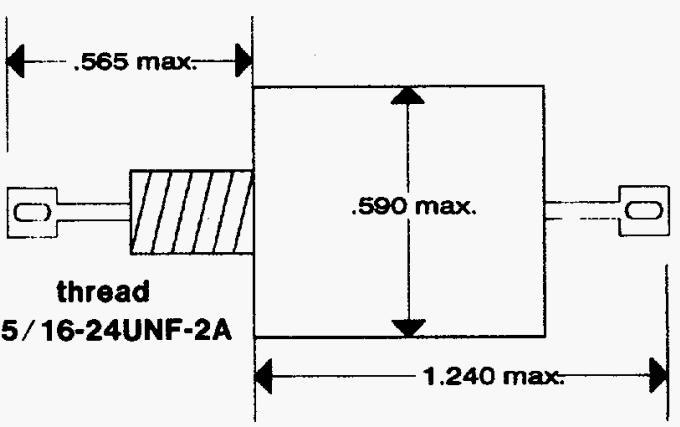

MC2944

Figure 4. MC Family of Filters. 


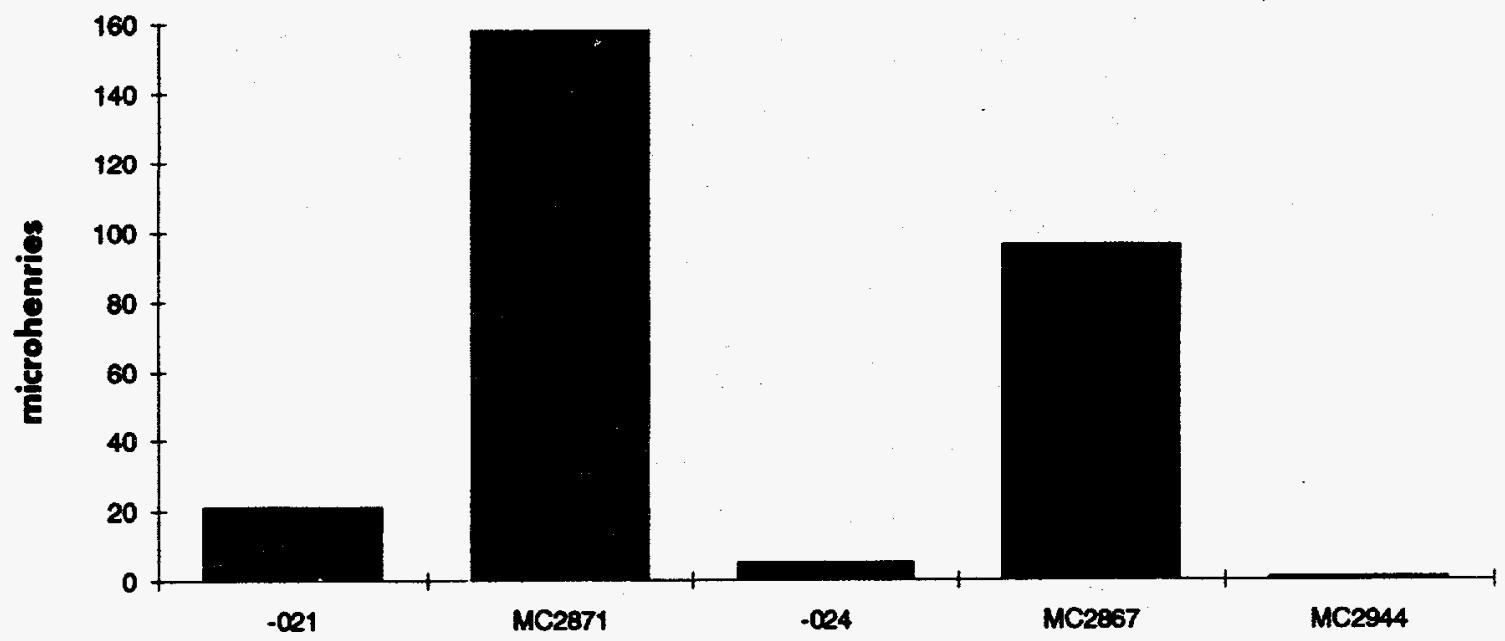

Figure 5. Average Inductance (uH) for MC2871, MC2867, and MC2944.

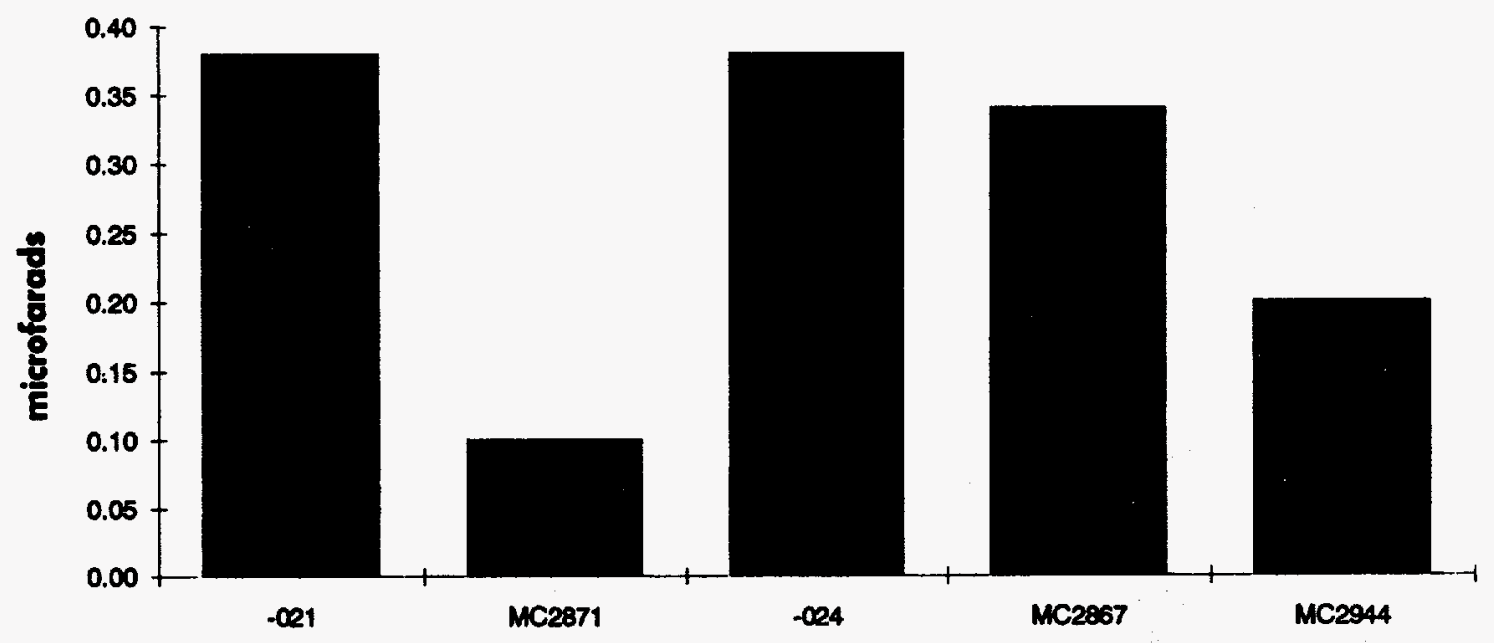

Figure 6. Average Capacitance (uF) for MC2871, MC2867, and MC2944. 


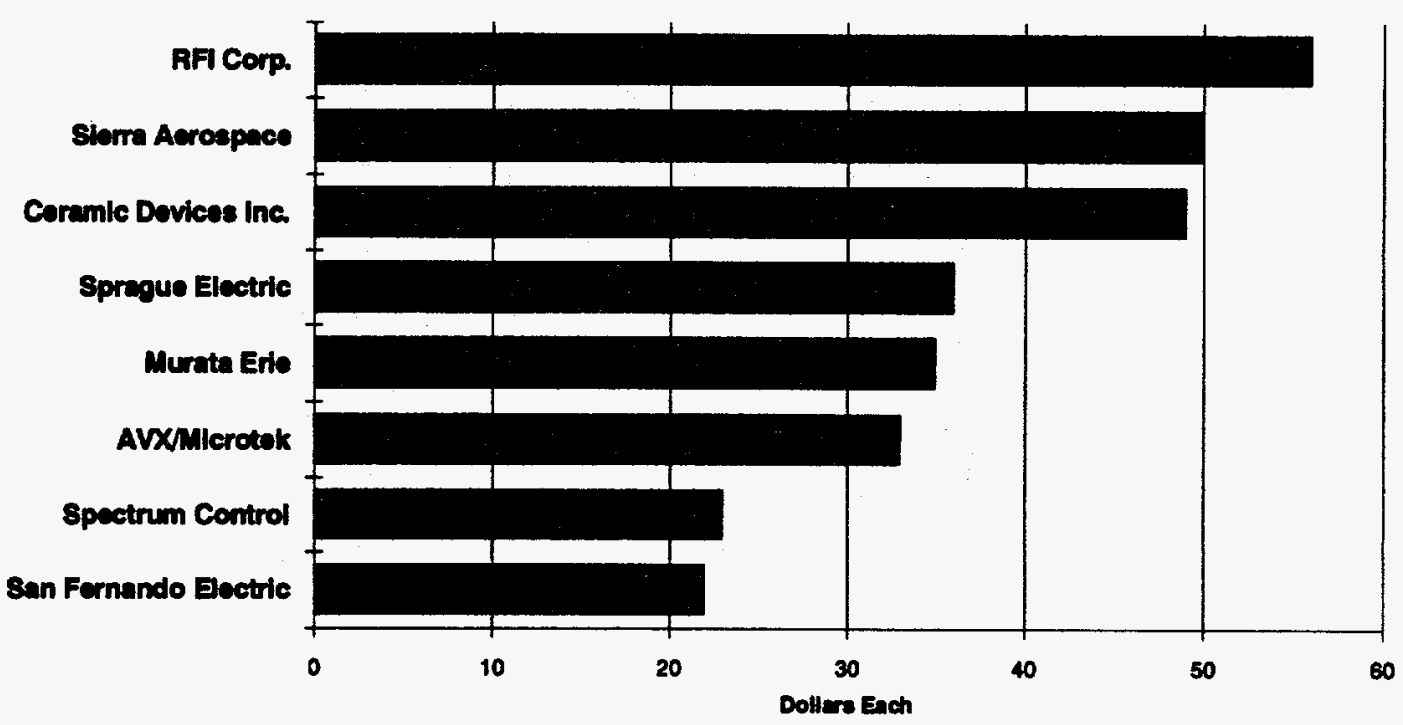

Figure 7. Mil-F-28861/5-021 Small Quantity Prices.

Table 4. Comparison of Electrical Characteristics Among Suppliers.

\begin{tabular}{lccc} 
& \multicolumn{3}{c}{ Average Values (Mil-F-28861/5-021 } \\
\cline { 2 - 4 } Supplier & $\begin{array}{c}\text { Inductance } \\
\text { (uH) }\end{array}$ & $\begin{array}{c}\text { DC Resistance } \\
\text { (ohm) }\end{array}$ & $\begin{array}{c}\text { Capacitance } \\
\text { (ufd) }\end{array}$ \\
\hline AVX & 20 & .03 & .40 \\
CDI & 57 & .05 & .38 \\
Murata & 21 & .03 & .27 \\
RFI & 15 & .02 & .58 \\
Sierra & 22 & .04 & .46 \\
SFE & 23 & .03 & .42 \\
Spectrum & 25 & .04 & .37 \\
Sprague & 17 & .02 & .46 \\
Figure & 8 & 9 & 10 \\
\hline \hline
\end{tabular}

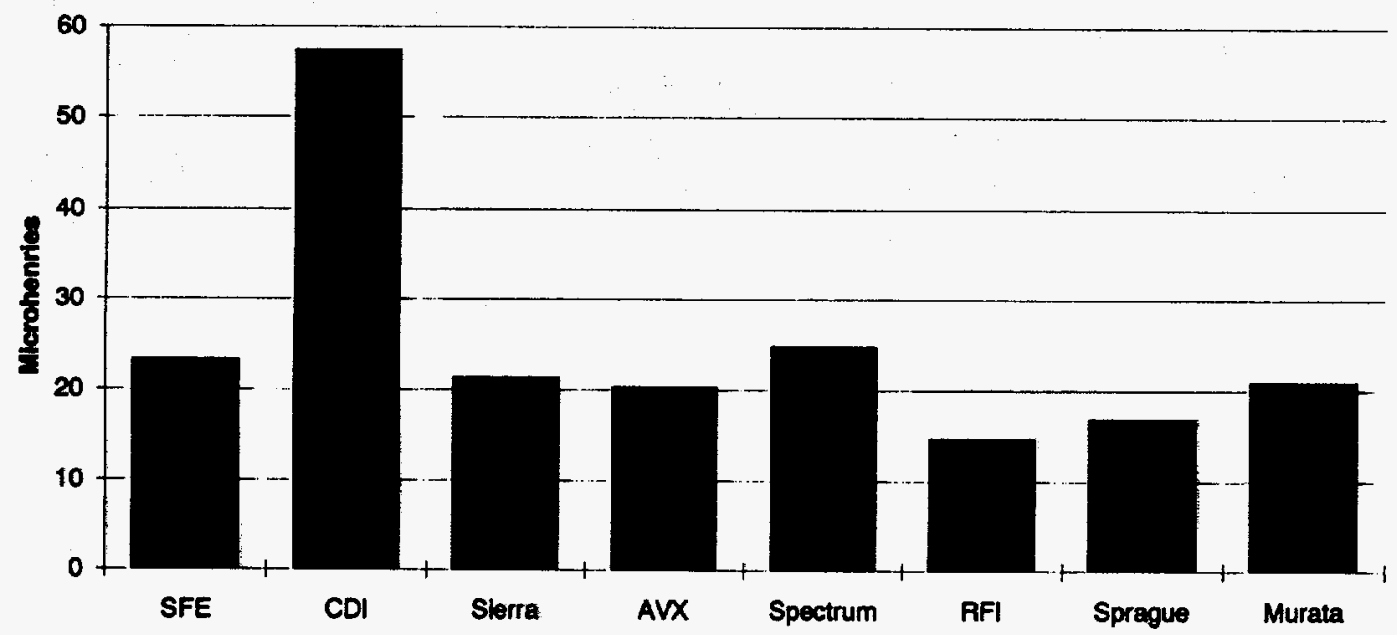

Figure 8. Mil-F-28861/5-021 Average Inductance. 


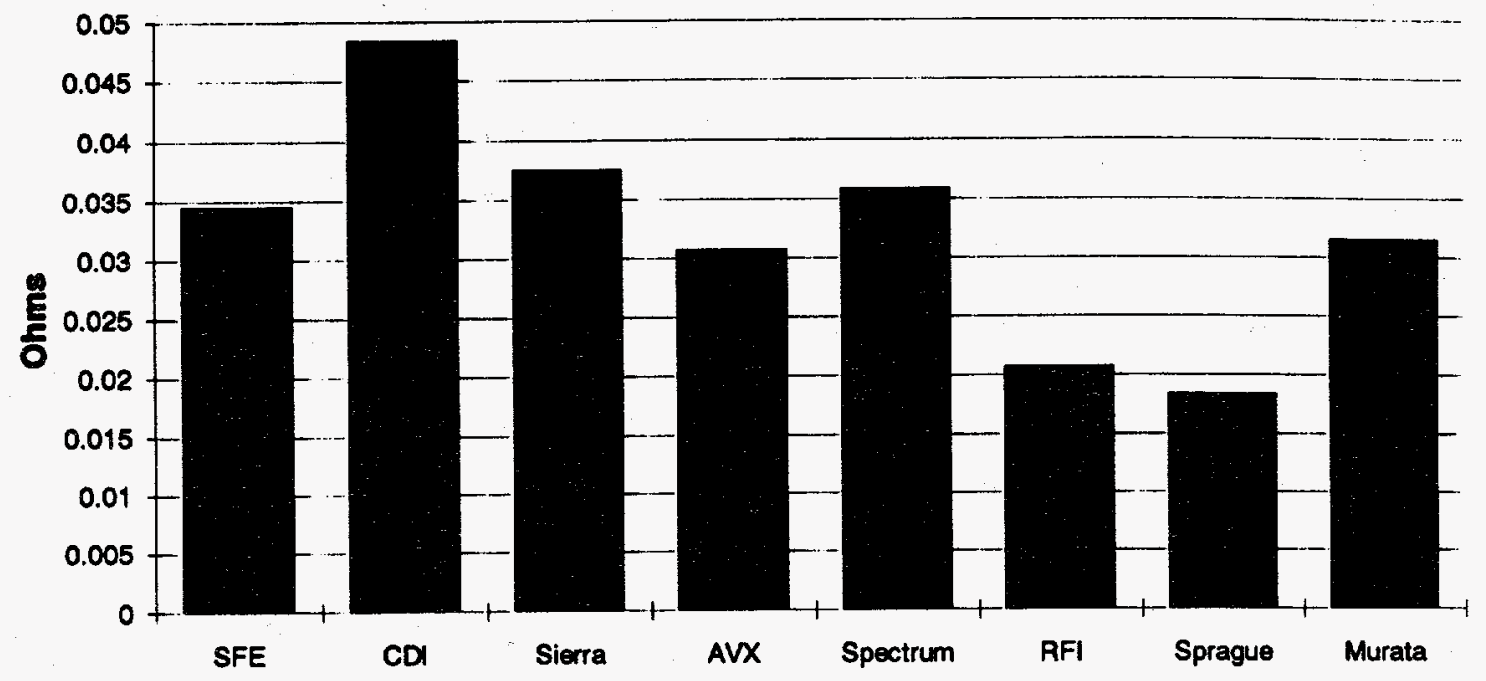

Figure 9. Mil-F-28861/5-021 Average DC Resistance.

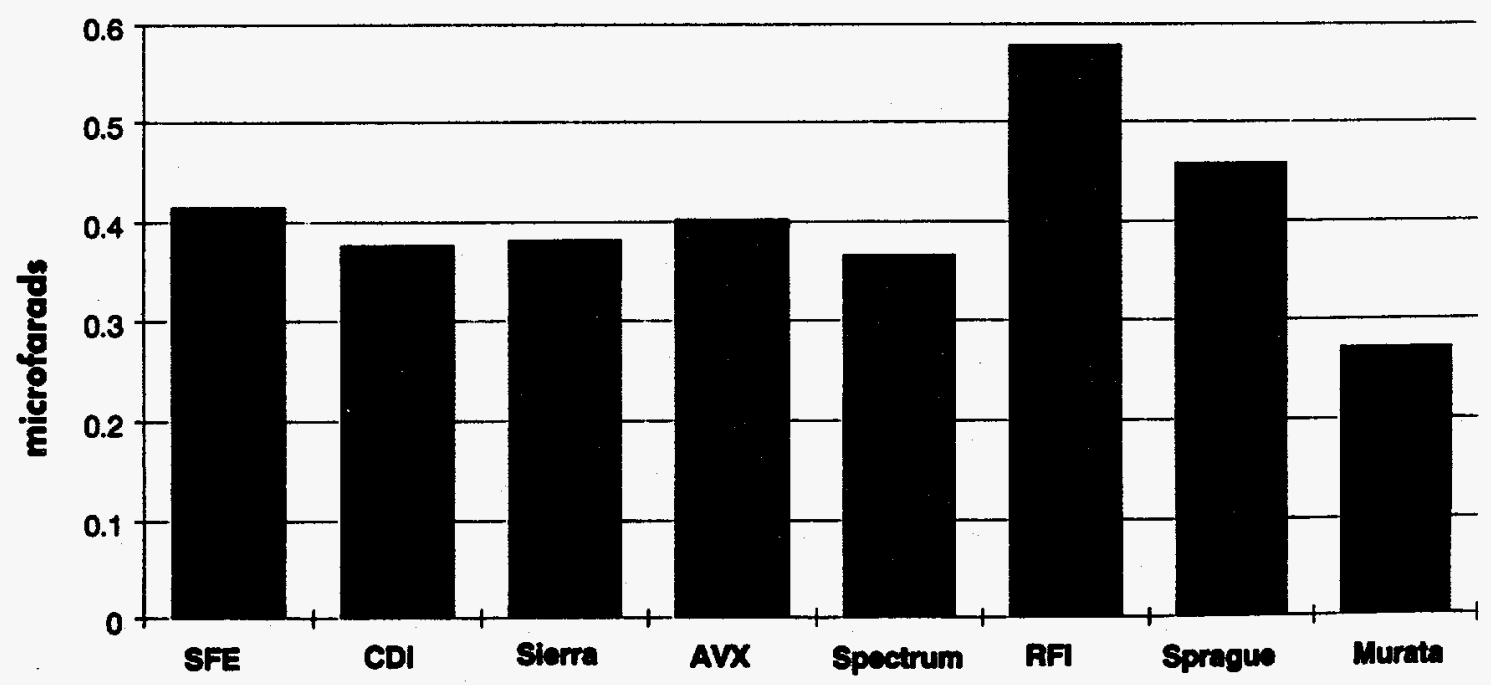

Figure 10. Mil-F-28861/5-021 Average Capacitance. 


\section{Evaluation Test Plan}

Filter samples (Mil-F-28861/5-021) were divided into four groups for testing and examination according to Table 5. The main test sequence consisted of the tests shown in table 6 .

Table 5. Group Testing of Filters.

\begin{tabular}{lc} 
Group Name & $\begin{array}{c}\text { Sample Quantity } \\
\text { Per Supplier }\end{array}$ \\
\hline Main Test Sequence & 25 \\
Thermal Cycling & 10 \\
Destructive Physical Analysis & 4 \\
Solderability & 10 \\
\hline \hline
\end{tabular}

The Thermal Cycling test sequence consisted of a group of five basic electrical tests to be performed before and after cycling the filters between $-55^{\circ}$ and $+125^{\circ} \mathrm{C}$. Those tests are (1) Insulation Resistance (IR), (2) Inductance, (3) Inductance with DC Bias, (4) Capacitance, and (5) DC Resistance. Each thermal cycle consisted of one-hour soaks at each temperature extreme with a one-hour transition time. The electrical tests were performed after 50 cycles, 150 cycles, and 300 cycles. We performed failure analysis as necessary.

The Destructive Physical Analysis (DPA) consisted of (1) creating a potted cross section of one filter from each supplier, (2) pealing the case open on two filters from each supplier, (3) cross-sectioning one capacitor from each supplier, and (4) conversations with suppliers. The potted cross sections and filters opened by pealing the case were used to see how the filters were constructed. This aided the analysis of failures from the other test sequences and enabled some value judgments to be made regarding filter design. Conversations with suppliers supplemented the observations for value judgments and provided more information for characterization. We used the capacitor cross sections to document the designs in terms of dimensions of dielectric layers and internal plates.

Solderability testing was performed at Allied Signal, KCD, by the same inspectors that may be called upon to test incoming material. Method 208 of MILSTD-202 was used, which requires $95 \%$ coverage of surfaces dipped into a solder pot.

\section{Test Results}

\section{Device Characterization}

Table 7 outlines the items presented in this section.

X-ray (Main Test Sequence). Examples of X-ray photographs are provided in Figure 11. They are labeled to give an idea of the criteria used to classify the observations. Figure 12 shows our tally of assembly observations.

Leak Testing (Main Test Sequence). Filters were tested for gross leaks and fine leaks (Figure 13). In production, the MC filters were only tested for gross leaks. This, coupled with the fact that fine leak testing can be confounded by inadequate cleaning or features that can absorb or trap gasses, led to our using only the gross leak tally as the parameter for judging suppliers. However, the fine leak data is provided for reference. The high rate of RFI seal failures is design related because most of the leaks occurred at the hole in the side of the case that is solder-sealed after potting the coil. No other suppliers have a break (hole) of this type in the case.

Insulation Resistance (Main Test Sequence). Higher values of IR are desirable over lower values, and IR inherently decreases with increased capacitance (Figures 14 and 15). Because of this relationship between IR and capacitance, Gohm $\times$ ufd is typically used as shown in figure 14 .

Inductance with DC Bias (Main Test Sequence). It is desirable to maintain inductance as the conducted DC current increases; however, it is natural for the inductance to decrease as the toroidal core saturates with magnetic flux produced by the current. The amount of inductance decrease can be controlled by core material selection, but a tradeoff develops between inductance decrease and the nominal inductance achieved within a given package size. Cores with higher permeability produce more inductance but suffer more with bias current. Because the Mil-Standard filters do not have requirements for inductance decrease, they were not judged for that parameter. However, the measurements were taken and provided in Figure 16. As we develop specifications for filters based on the Mil-Standard designs, we expect to specify core permeability and minimum inductance with DC bias. 
Table 6. Main Test Sequence.

Test

X-ray

Gross Leak

Fine Leak

Transient Dielectric Strength

High Power

DC Dielectric Strength

Insulation Resistance (IR)

Inductance

Inductance with DC Bias

Capacitance

DC Resistance

Attenuation (Lo Freq)

Attenuation (Hi Freq)

Hot IR

Inductance vs Temperature

Capacitance vs Temperature

Temperature Shock

Hi-Freq Vibration

Random Vibration

Mechanical Shock

Insulation Resistance

Inductance

Inductance with DC Bias

Capacitance

Gross Leak

Failure Analysis
Conditions

Two views with parts rotated $90^{\circ}$ examined for solder balls, internal debris, and position of internal parts.

Bubble test per Method 112, Condition D, of Mil-STD-202 -

Six applications of $500 \mathrm{~V}$ half-sine pulse with $10-20 \mu \mathrm{sec}$ period $>200 \mathrm{~V}, 500 \mu \mathrm{sec}$ between pulses, PT3082 used, no arcing or breakdown allowed.

PT3082 used to supply $2 \mathrm{MHz}, 800 \mathrm{ma}$ signal. Filter output voltage maximums specified in MC product specification with $\mathrm{Hi} \mathrm{Z}$ load.

200 VDC for $120 \pm 5$ sec., no arcing or breakdown allowed.

From input terminal to case at $200 \mathrm{~V}$.

From terminal to terminal at $1 \mathrm{kHz}$.

From terminal to terminal at $1 \mathrm{kHz}$ with 2 amps $\mathrm{DC}$ bias.

From terminal to case at $1 \mathrm{kHz}$.

From terminal to terminal.

$100 \mathrm{kHz}$ to $2 \mathrm{MHz}$ on HP3577 Network Analyzer.

$100 \mathrm{MHz}$ to $15 \mathrm{GHz}$ on HP8510 Network Analyzer.

From input terminal to case at $200 \mathrm{~V}$ and $+125^{\circ} \mathrm{C}$.

$-55^{\circ} \mathrm{C}$ and $+125^{\circ} \mathrm{C}$ at $1 \mathrm{kHz}$.

$-55^{\circ} \mathrm{C}$ and $+125^{\circ} \mathrm{C}$ at $1 \mathrm{kHz}$

Five cycles of $-55^{\circ} \mathrm{C}$ to $+125^{\circ} \mathrm{C}$ with 4 -hour soak times at extremes.

Twelve cycles of 20 minutes each per each of 3 axes, from 20 to $3000 \mathrm{~Hz}, 50 \mathrm{~g}$.

Three minutes in each of 2 axes from 20 to $2000 \mathrm{~Hz}, 0.03 \mathrm{~g}^{2} / \mathrm{Hz}$.

$275 \mathrm{~g}$ haversine of $5.5 \mathrm{msec}$ duration, 3 shocks in each of 6 axes.

From input terminal to case at $200 \mathrm{~V}$.

From terminal to terminal at $1 \mathrm{kHz}$.

From terminal to terminal at $1 \mathrm{kHz}$ with 2 amps DC bias.

From terminal to case at $1 \mathrm{kHz}$.

Bubble test per Method 112, Condition D, of Mil-STD-202.

As needed.

Table 7. Overview of Testing.

\begin{tabular}{|c|c|c|c|}
\hline Test Group & Test & Nature of Presentation & Figure \\
\hline \multirow[t]{9}{*}{ Main Test Sequence } & X-ray & Tally of assembly flaws & 11,12 \\
\hline & Gross leak/fine leak & Seal failure tally & 13 \\
\hline & Insulation resistance (IR) & Average and minimum & 14,15 \\
\hline & Inductance with DC bias & Inductance change & 16 \\
\hline & Attenuation & Response curves & 17 \\
\hline & Hot IR & Average and minimum & 18 \\
\hline & Inductance vs temp & Table of averages & - \\
\hline & Capacitance vs temp & Table of averages & - \\
\hline & Environmental stress & Seal failure tally & 19 \\
\hline Thermal Cycling & Capacitance & Standard deviation of capacitance & 20 \\
\hline Destructive Physical Analysis & Construction notes & - & - \\
\hline Solderability & Solderability & Discussion & - \\
\hline
\end{tabular}



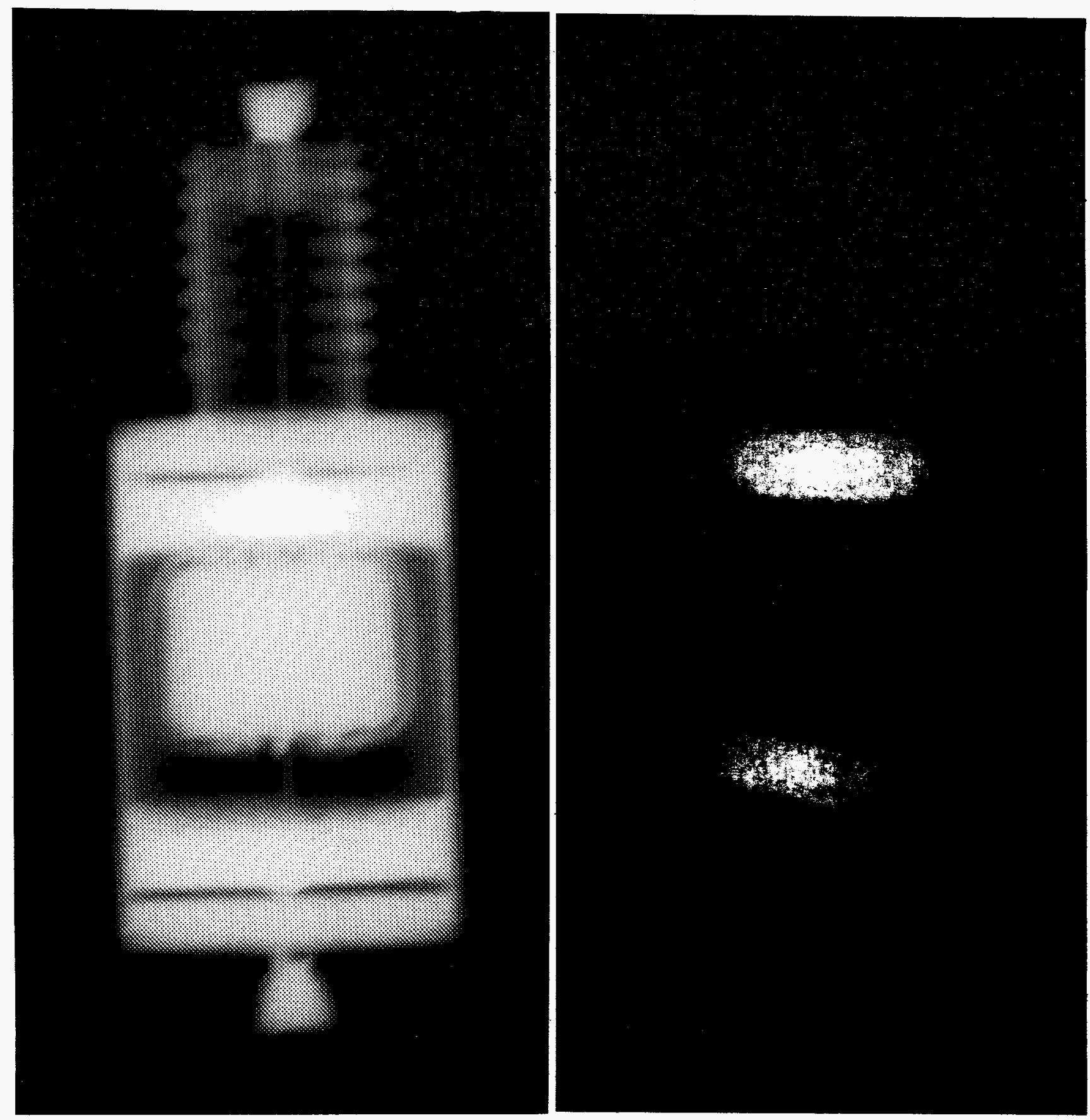

Good Filter Assembly

Assembly Flaw (Crooked)

Figure 11. X-ray Photographs. 
Mil-F-28861 Assembly Consistency

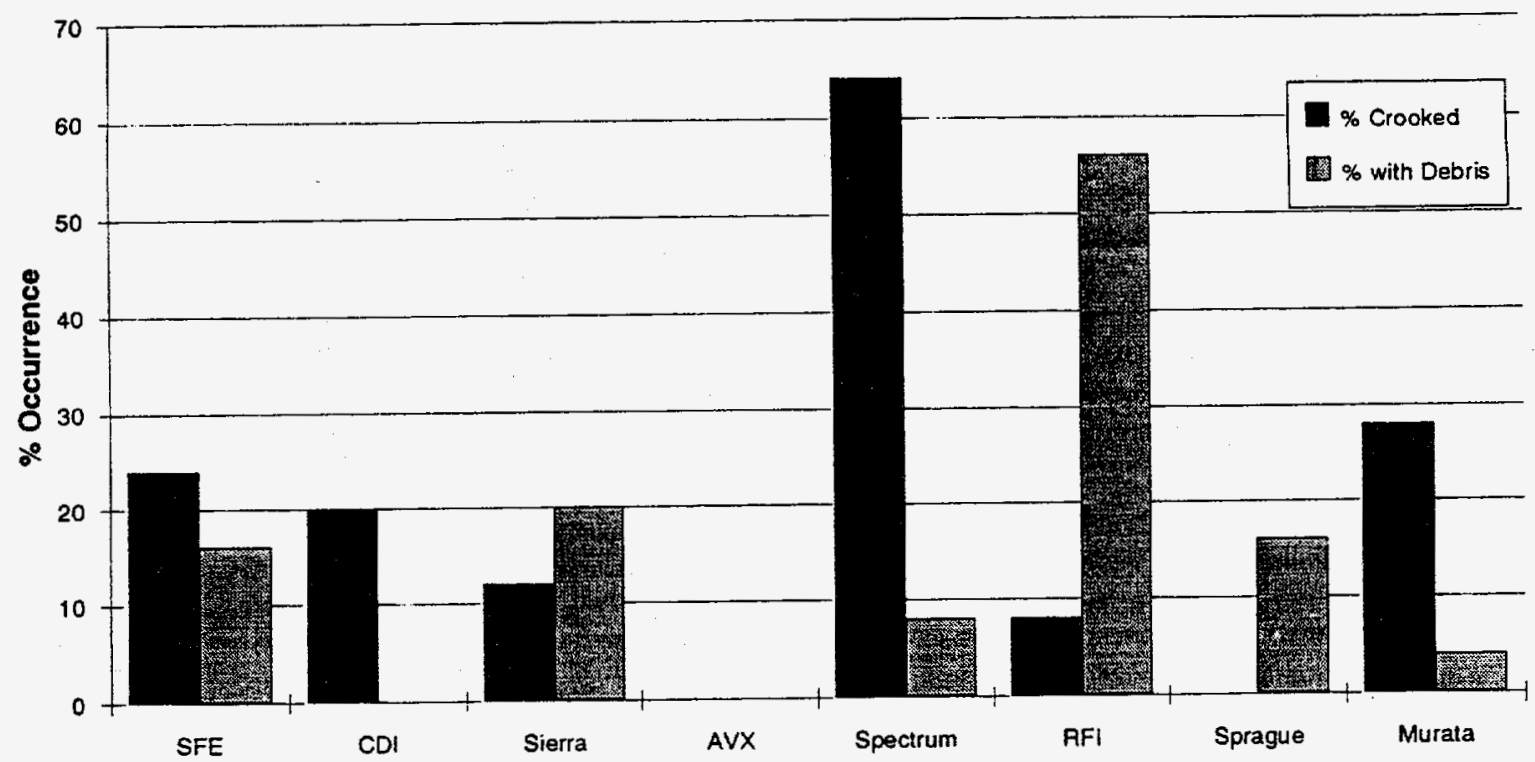

Figure 12. Mil-F-28861 Assembly Consistency.

Mil-F-28861/5 Leak Test Results March 5, 1992

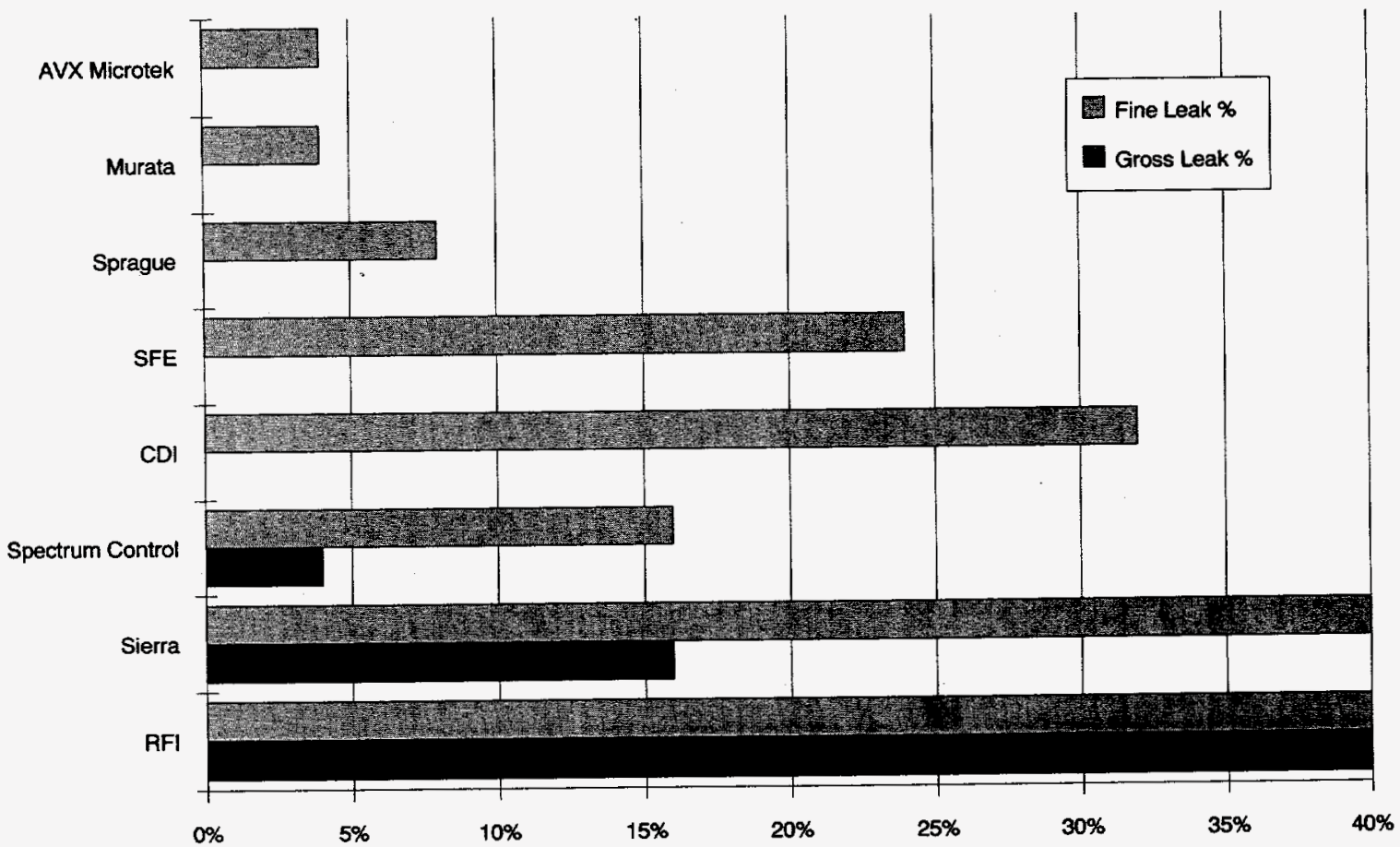

Figure 13. Mil-F-28861 Leak Test Failures. 
Mil-F-28861 Insulation Resistance (Room Temp)

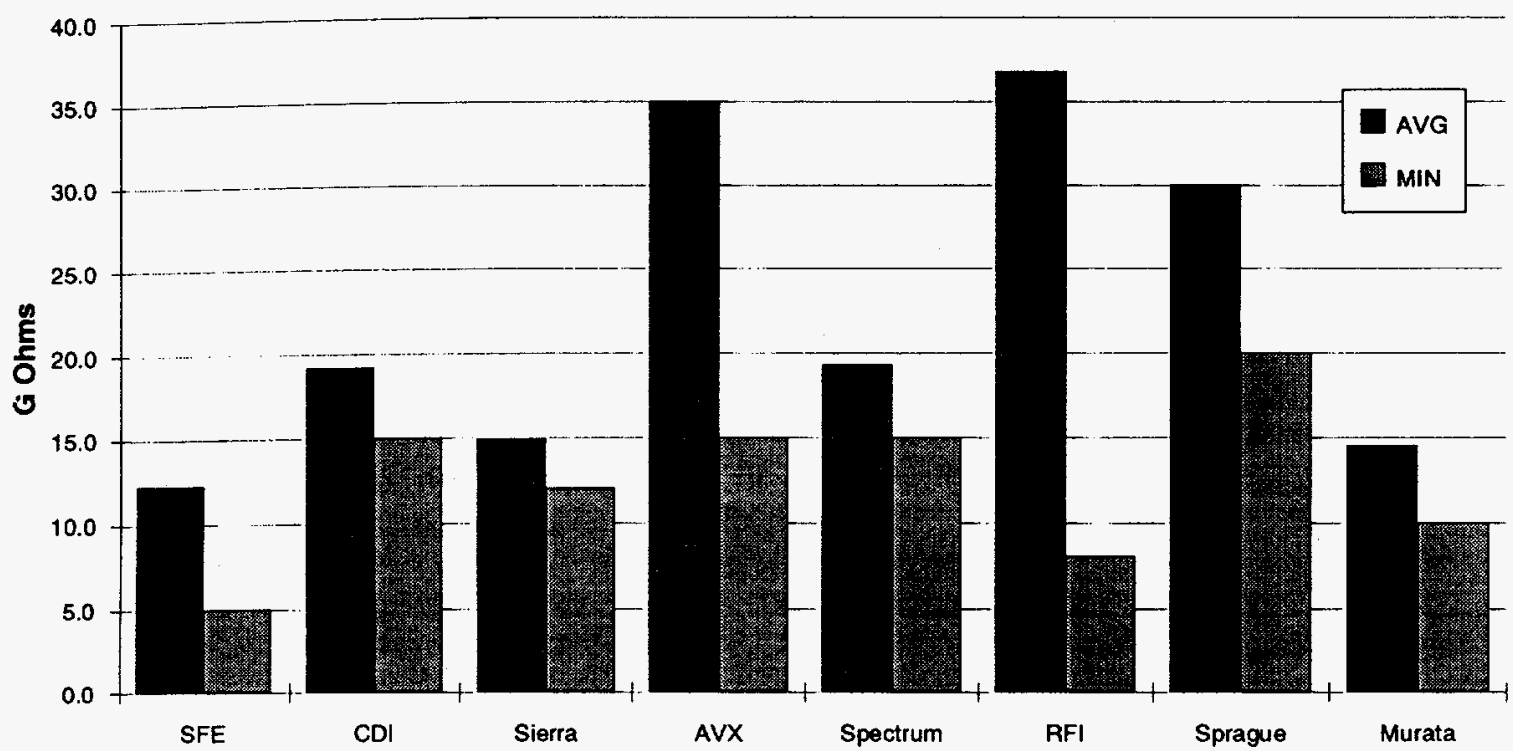

Figure 14. Mil-F-28861 Insulation Resistance at Room Temperature.

Room Temperature IR in Gohm $x$ ufd

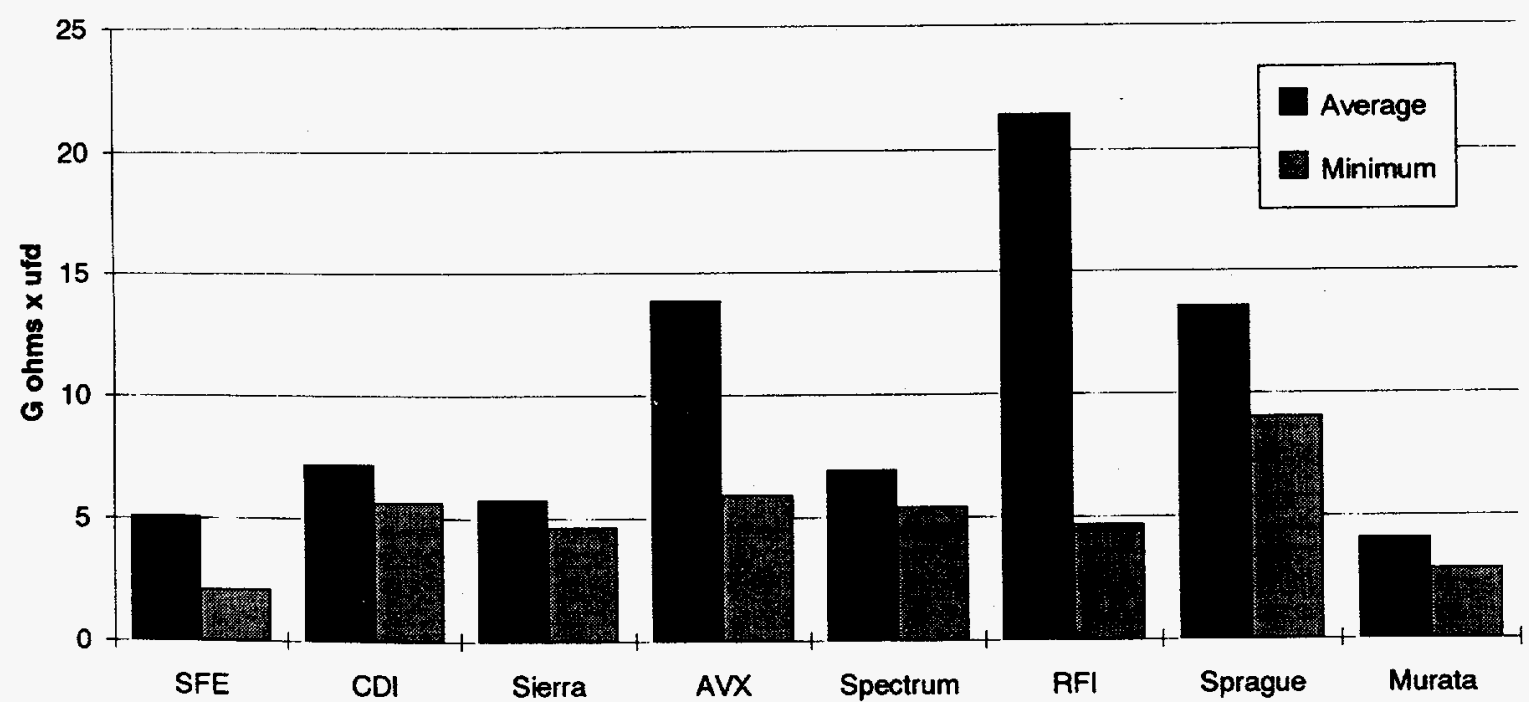

Figure 15. Room Temperature Insulation Resistance in Gohm $\times$ ufd. 


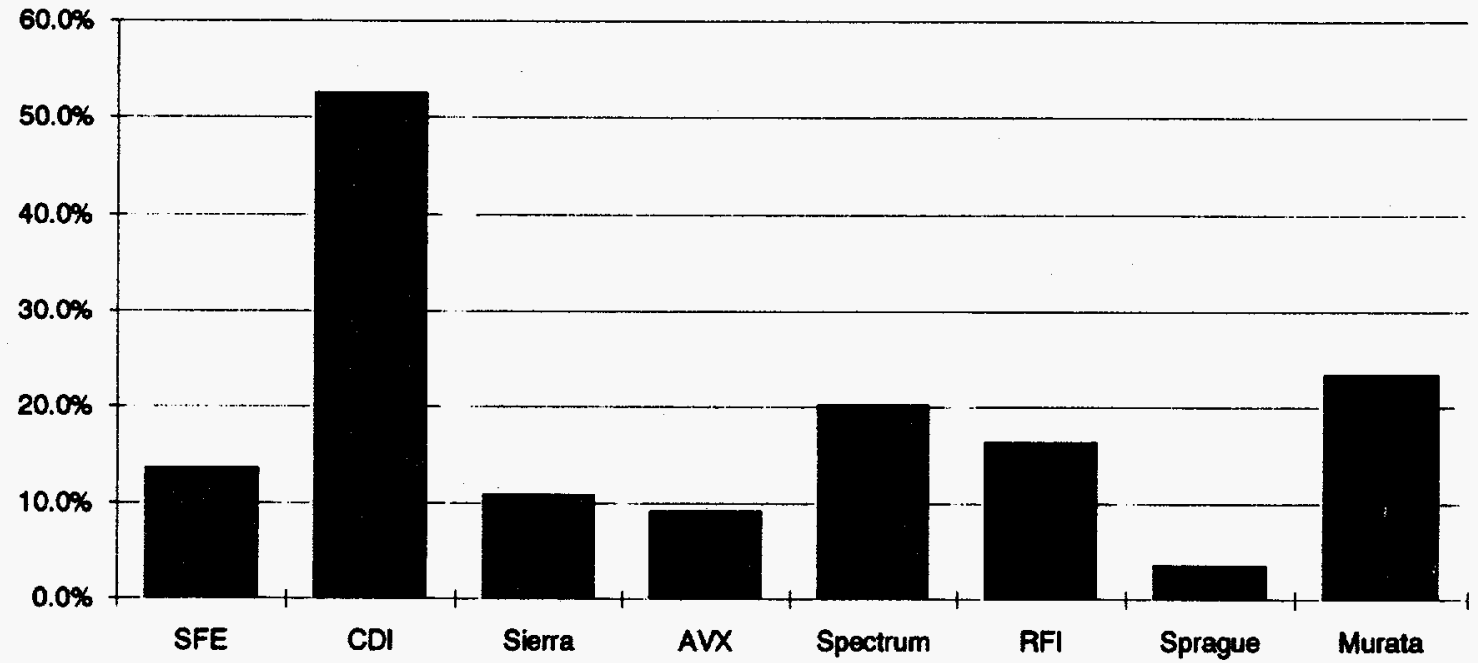

Figure 16. Mil-F-28861/5-021 Inductance Change with 2 Ampere Load.

Attenuation (Main Test Sequence). The Mil-F28861/5-021 filters meet the attenuation requirements of MC2871. Typical performance can be seen in Figure 17.

Hot Insulation Resistance (Main Test Sequence). The Hot IR performance of CDI filters was marginal, and the filter with the lowest value was destructively analyzed (Figure 18). The analysis is discussed in the following section, Failure Analysis. To put the numbers in perspective, the minimum requirement for the MC2871 is $500 \mathrm{M} \Omega$, which calculates to $0.05 \mathrm{G} \Omega$ ufd.

Inductance and Capacitance vs Temperature (Main Test Sequence). The MC filters specify inductance and capacitance at the temperature extremes of $-55^{\circ} \mathrm{C}$ and $+125^{\circ} \mathrm{C}$. The Mil-Standard filters specify neither but require minimum attenuation to be achieved across that temperature range. Inductance and capacitance of Mil-Standard filters were measured at the temperature extremes and the values normalized to the room temperature measurement. For reference, the averages appear in Table 8.

Environmental Stress (Main Test Sequence). Filters were subjected to thermal shock, highfrequency vibration, random vibration, and mechanical shock without being measured between each applied stress. Post-stress failures were observed as gross leak failures increased, and in one of the CDI filters, IR degraded. Eighteen of the twenty-five sam- ples from SFE ( $72 \%$ ) failed because of a disconnection of the coil wire. As a result, the measurable capacitance would be reduced to one-half of its original value, but the root cause was the coil disconnect. The hermetic seal test results are summarized in Figure 19, and the CDI and SFE filters will be discussed in the Failure Analysis section.

Thermal Cycling. After 150 cycles, two filters showed significantly reduced capacitance. One from Spectrum Control dropped from 0.36 ufd to 0.20 ufd in total capacitance, and one from Sierra went to one-half of its original value. The failures were still evident after 300 cycles. Before commencing destructive analysis, we determined which capacitor had failed in each case. One of the Spectrum capacitors failed internally, dropping to only $15 \mathrm{nfd}$. The Sierra filter had an internal assembly flaw that allowed one capacitor to be disconnected from the coil wire. Both of these cases will be explained in more detail in the Failure Analysis section. The standard deviation of capacitance was computed before and after cycling (Figure 20).

Destructive Physical Analysis. As stated before, all except Sprague and SFE use potting to restrict coil motion. Sprague designed a tight internal fit and rolls the shell over the glass-sealed end cap to keep it snug. Apparently, SFE's assembly methods are not quite as effective because environmental stress created failures (see Environmental Stress in this section). 


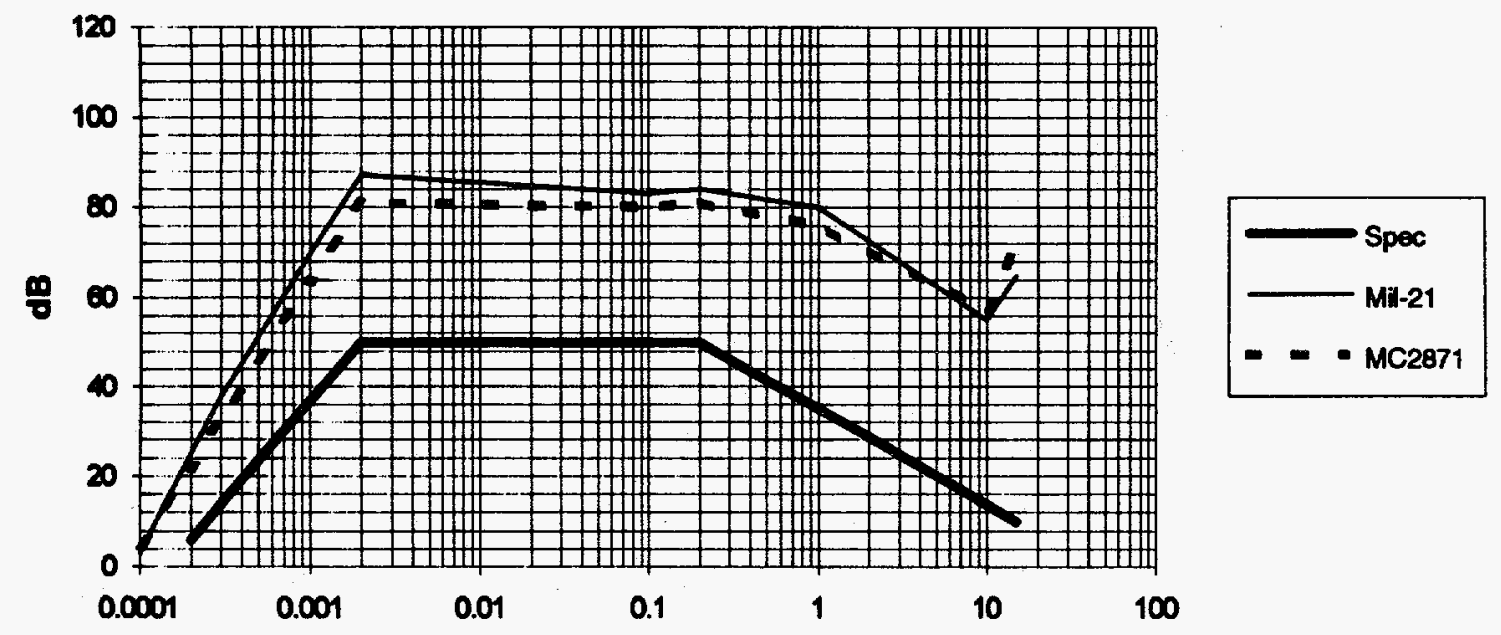

Figure 17. Attenuation Performance vs MC2871 Specification. 28861/5-021

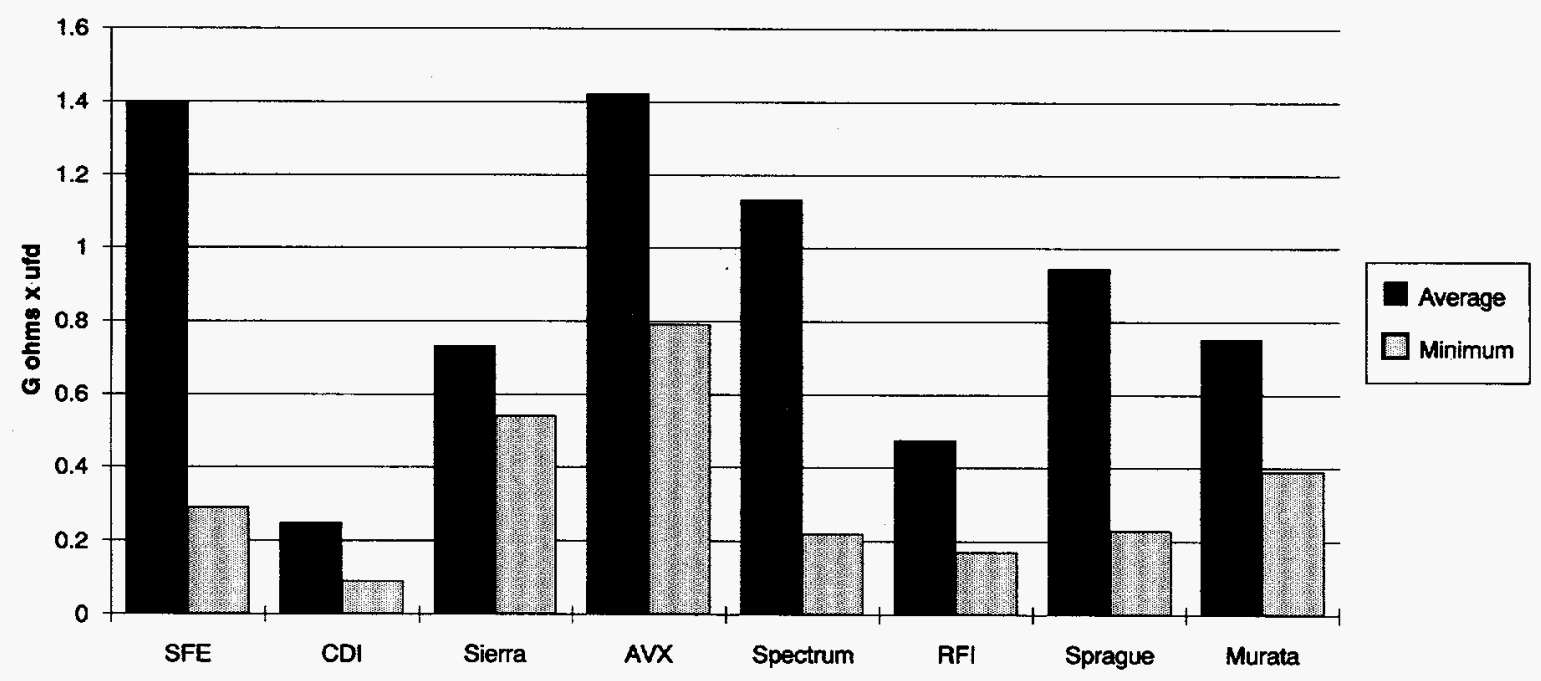

Figure 18. Mil-F-28861/5-021 Hot $\left(125^{\circ} \mathrm{C}\right)$ Insulation Resistance (Adjusted for Capacitance Value). 
Table 8. Inductance and Capacitance Averages.

\begin{tabular}{lccccccc} 
& \multicolumn{3}{c}{ Inductance } & & \multicolumn{3}{c}{ Capacitance } \\
\cline { 2 - 4 } \cline { 6 - 8 } Supplier & $-55^{\circ} \mathrm{C}$ & $25^{\circ} \mathrm{C}$ & $125^{\circ} \mathrm{C}$ & & $-55^{\circ} \mathrm{C}$ & $25^{\circ} \mathrm{C}$ & $125^{\circ} \mathrm{C}$ \\
\hline SFE & 1.03 & 1 & 1.04 & & 0.94 & 1 & 1.03 \\
CDI & 0.69 & 1 & 0.82 & & 0.95 & 1 & 0.91 \\
Sierra & 1.16 & 1 & 1.19 & & 0.87 & 1 & 0.90 \\
AVX & 0.97 & 1 & 0.97 & & 0.93 & 1 & 0.89 \\
Spectrum & 1.00 & 1 & 1.00 & & 0.96 & 1 & 1.03 \\
RFI & 0.91 & 1 & 0.91 & & 0.92 & 1 & 0.87 \\
Sprague & 0.90 & 1 & 0.92 & & 0.88 & 1 & 0.89 \\
Murata & 1.01 & 1 & 1.05 & & 0.96 & 1 & 0.98 \\
\hline \hline
\end{tabular}

Gross Leak Failures- Mil-F-28861/5-021

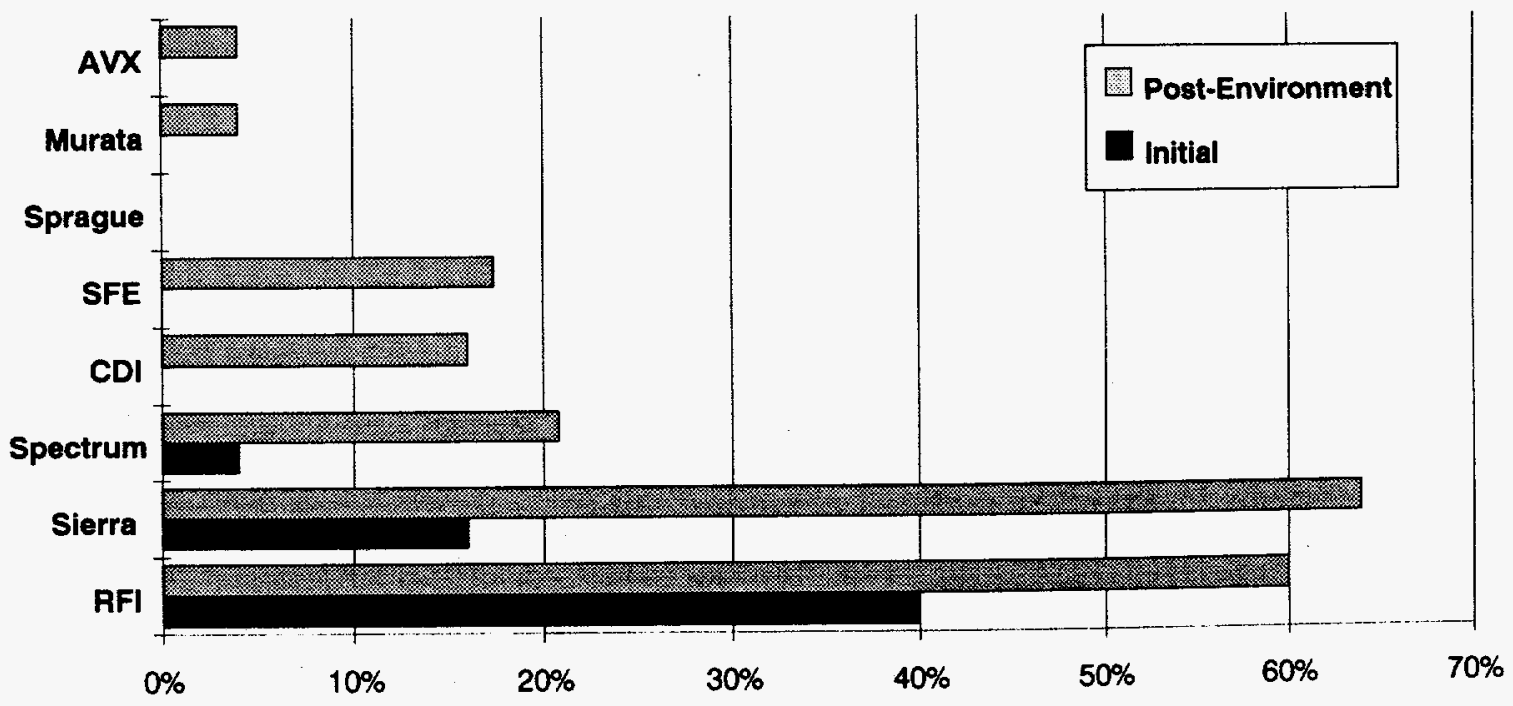

Figure 19. Mil-F-288611/5-021 Gross Leak Failures. 


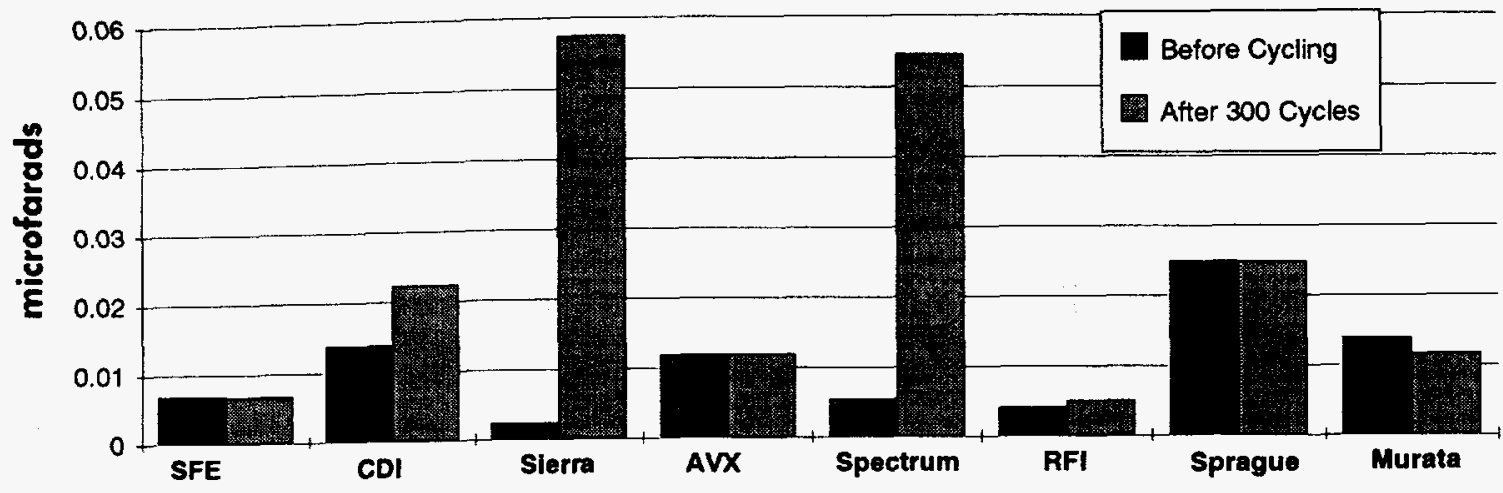

Figure 20. Mil-F-28861/5-021 Capacitance Sigma Before and After Cycling.

Another difference between suppliers is the design of the shell and glass seals. Sprague and AVX use extruded shells, which are simple pieces of brass tubing. These inexpensive parts are sealed by soldering on glass-sealed end caps. The end caps are purchased with glass-to-metal seals formed at the outside diameter (steel ring) and in the center where the terminal (typically Kovar) passes. The threaded end of the filter has less glass material, and the steel ring described above is machined as a threaded neck. An alternate design uses shells machined out of a metal rod and therefore can have the threaded neck machined as part of the shell. The opposite (output) end of the machined shell appears and is sealed as in the case of the extruded shell.

Spectrum Control has the glass seals and terminals installed into the threaded end before purchasing them as a piece-part. The others use a very small glass-sealed terminal with metal outer ring and solder it into the threaded neck of the machined shell. In all cases, the terminals are metal tubes flattened into a flag on one end to provide a place to solder wires in the final installation by the user. The tubes, which are sealed with high-temperature solder in the final assembly operation, also electrically connect the coil wire to the terminals. Table 9 describes some of the construction differences. The number of solder seals listed does not include the sealing of the terminal just mentioned.

Sierra Aerospace's design of internal parts is unique, and although it may offer advantages in some respects, it contributed to the failure during thermal cycling. It will be discussed in the following section, Failure Analysis.

The pierced shell mentioned in the notes for RFI refers to a small hole machined into the shell about midway along its length. This corresponds to the location of the coil. After the first capacitor and coil are installed, a low-viscosity potting resin is forced through the hole. After cleaning, the hole is sealed with solder.

Tables 10 through 12 show some of the materials used by each supplier, including the type of solder used in the various locations. Solders are selected to avoid subsequent reflow after parts are installed while still allowing the user to attach wires. 
Table 9. Construction Notes.

\begin{tabular}{|c|c|}
\hline Supplier & Construction Description \\
\hline AVX & $\begin{array}{l}\text { Belt and Iron Reflow, Inert Atmosphere, Extruded Shell, } \\
\text { Potted Coil, Post-Assy Plating, Solder Seals (2) }\end{array}$ \\
\hline CDI & Iron Soldering, Machined Shell, Potted Coil, Solder Seals (2) \\
\hline Murata & $\begin{array}{l}\text { Torch and Iron Reflow, Inert Atmosphere, Machined Shell, } \\
\text { Potted Coil, Solder Seals (2) }\end{array}$ \\
\hline RFI & $\begin{array}{l}\text { Iron, Torch, and Belt Reflow, Machined Shell, Potted Coil, } \\
\text { Pierced Shell, Solder Seals ( } 2)\end{array}$ \\
\hline Sierra & $\begin{array}{l}\text { Iron Soldering, Machined Shell, Potted Coil, Capacitor Rings, } \\
\text { Coil Wire Tubelet, Solder Seals (2) }\end{array}$ \\
\hline SFE & Unpotted Coil, Machined Shells, Solder Seals (2) \\
\hline Spectrum & Iron Soldering, Machined Shell, Potted Coil, Solder Seals (1) \\
\hline Sprague & $\begin{array}{l}\text { Convection Oven and Iron Reflow, Extruded Shell, Unpotted } \\
\text { Coil, Post-Assy Plating, Solder Seals (2) }\end{array}$ \\
\hline
\end{tabular}

Table 10. Materials for Thread, Case, and Output Headers.

\begin{tabular}{lllc} 
Supplier & $\begin{array}{c}\text { Thread } \\
\text { Material }\end{array}$ & $\begin{array}{c}\text { Case (Shell) } \\
\text { Material }\end{array}$ & $\begin{array}{c}\text { Output Header } \\
\text { (Ring) Material }\end{array}$ \\
\hline Sprague MC2871 & Steel & Brass & Steel \\
Sprague MC2867 & Brass & Brass & Steel \\
Sprague MC2944 & Steel & Brass & Steel \\
Sprague Mil-28861 & Steel & Brass & Steel \\
AVX & Steel & Brass & Steel \\
CDI & Brass & Brass & Steel \\
Sierra & Steel & Steel & Steel \\
Spectrum & Steel & Steel & Steel \\
RFI & Brass & Brass & Steel \\
SFE & Steel & Steel & Steel \\
\hline \hline
\end{tabular}


Table 11. Connections.

\begin{tabular}{|c|c|c|c|c|c|}
\hline Supplier & $\begin{array}{c}\text { Cap } \\
\text { to Shell }\end{array}$ & $\begin{array}{c}\text { Cap } \\
\text { to Wire }\end{array}$ & $\begin{array}{l}\text { Wire } \\
\text { to Terminal }\end{array}$ & $\begin{array}{c}\text { Glass Seal } \\
\text { to Shell }\end{array}$ & $\begin{array}{c}\begin{array}{c}\text { Cap to Cap } \\
\text { Housing }\end{array} \\
\end{array}$ \\
\hline AVX & $\begin{array}{l}\text { 1st } 10 / 88 / 2 \\
\text { 2nd Sn } 96\end{array}$ & $10 / 88 / 2$ & $10 / 88 / 2$ & Sn 60 & NA \\
\hline CDI & Sn 62 & Sn 96 & $\mathrm{Ag} 1.5$ & Sn 63 & NA \\
\hline SFE & - & - & - & - & - \\
\hline Sierra & $\begin{array}{l}\text { 1st Sn } 96 \\
\text { 2nd Sn } 63\end{array}$ & $\mathrm{Ag} 1.5$ & $\operatorname{Sn} 10$ & Sn 63 & Sn 10 \\
\hline Spectrum & Sn 62 & $95 / 3 / 2$ & $6 / 92.6 / 1.4$ & Sn 60 & NA \\
\hline Spectrum (AIt.) & $60 / 38 / 2$ & $96 / 4$ & 6/92.6/1.4 & Sn 60 & $\mathrm{NA}$ \\
\hline RFI & Sn 62 & $\operatorname{Sn} 10$ & Sn 10 & Sn 60 & NA \\
\hline Murata & - & - & - & - & - \\
\hline Sprague & $63 / 33 / 4$ & $95 / 5$ & $5 / 93 / 5 / 1.5$ & Sn 60 & NA \\
\hline Sprague MC2871 & $\begin{array}{l}63 / 33 / 4 \\
\mathrm{Sn} / \mathrm{Pb} / \mathrm{Ag} \\
\end{array}$ & $\begin{array}{l}95 / 5 \\
\mathrm{Sn} / \mathrm{Ag} \\
\end{array}$ & $\begin{array}{l}95 / 5 \\
\mathrm{~Pb} / \mathrm{Sn} \\
\end{array}$ & $\begin{array}{l}63 / 33 / 4 \\
60 / 40 \\
\end{array}$ & $\mathrm{NA}$ \\
\hline
\end{tabular}

Table 12. Solder Characteristics.

\begin{tabular}{lllll} 
Solder Type & Melt Temp & Tin \% & Lead \% & Silver \% \\
\hline Sn 10 & $268^{\circ} \mathrm{C}$ & 10 & 90 & - \\
Sn 60 & $183^{\circ} \mathrm{C}$ & 60 & 40 & - \\
Sn 63 & $183^{\circ} \mathrm{C}$ & 63 & 37 & - \\
Ag 1.5 & $309^{\circ} \mathrm{C}$ & 1 & 97.5 & 1.5 \\
Sn 96 & $221^{\circ} \mathrm{C}$ & 96.5 & - & 3.5 \\
Sn 62 & $183^{\circ} \mathrm{C}$ & 62 & 36 & 2 \\
$6 / 92.6 / 1.4$ & $296^{\circ} \mathrm{C}$ & 6 & 92.6 & 1.4 \\
$95 / 3 / 2$ & $225^{\circ} \mathrm{C}$ & 95 & 3 & 2 \\
$10 / 88 / 2$ & $268^{\circ} \mathrm{C}$ & 10 & 88 & 2 \\
$63 / 33 / 4$ & $179^{\circ} \mathrm{C}$ & 63 & 33 & 4 \\
$5 / 93.5 / 1.5$ & $301^{\circ} \mathrm{C}$ & 5 & 93.5 & 1.5 \\
$95 / 5$ & $301^{\circ} \mathrm{C}$ & 5 & 95 & - \\
$95 / 5$ & $221^{\circ} \mathrm{C}$ & 95 & - & 5 \\
$96 / 4$ & $183^{\circ} \mathrm{C}$ & 96 & - & 4 \\
\hline \hline
\end{tabular}




\section{Failure Analysis}

The failures discussed in this section are listed in Table 13.

Table 13. Overview of Failures.

\begin{tabular}{lll} 
Supplier & \multicolumn{1}{c}{ Symptom } & Time of Occurrence \\
\hline CDI & $\begin{array}{l}\text { Low insulation } \\
\text { resistance (hot) }\end{array}$ & $\begin{array}{l}\text { Main Test } \\
\text { Sequence, worse } \\
\text { after environ- } \\
\text { mental stress }\end{array}$ \\
CDI & $\begin{array}{l}\text { Incomplete solder } \\
\text { at capacitor O.D. }\end{array}$ & DPA \\
SFE & $\begin{array}{l}\text { Coil disconnect } \\
\text { Spectrum }\end{array}$ & $\begin{array}{l}\text { After environ- } \\
\text { mental stress }\end{array}$ \\
Sierra & $\begin{array}{l}\text { Capacitance } \\
\text { reduction }\end{array}$ & Thermal cycling \\
reduction & Thermal cycling
\end{tabular}

CDI (Low Insulation Resistance). Figure 18 shows that CDI had the lowest performance for hot IR after adjusting for capacitance. After completing the remaining tests in the Main Sequence, some of the CDI filters were cleaned and retested for hot IR. Two filters were less than $500 \mathrm{M} \Omega$ at $125^{\circ} \mathrm{C}$, measuring $450 \mathrm{M} \Omega$ and $220 \mathrm{M} \Omega$, respectively. The condition warranted further investigation, although they were not true failures. The specification for MC filters is $500 \mathrm{M} \Omega$ minimum, and the Mil-F-28861 requires only $100 \mathrm{M} \Omega$ minimum. After returning to room temperature, one filter degraded further to $75 \mathrm{M} \Omega$ at only 25 volts. E. K. Beauchamp and S. L. Monroe, of the Glass and Electronic Ceramics Department, Sandia National Laboratories, dissected the filter and analyzed the capacitors. They discovered cracks and an electrical breakdown site that were caused by delamination between ceramic and conductive layers (Figure 2). The delamination could have occurred during thermal cycling when axial stresses develop because of thermal expansion mismatches between metals and ceramic. The stress development may have been compounded by lack of supporting solder between the capacitor and the filter shell described in the following paragraph. The metalization layers were not as continuous as they are in good capacitors, and there were very few "necks" of barium titanate that bridge through the conductive layer.
CDI (Incomplete Solder at Capacitor O.D.). The DPA revealed that, on many of CDI's filters, the potting prevents the output capacitor (nonthreaded end) from getting an optimum solder bond to the shell at its outside diameter. It appears that the potting is cured with the input capacitor and coil in place before the output capacitor is placed into the assembly. The shape of the cured potting compound is such that a thin meniscus is formed that clings to the shell a significant distance from the main body of the coil. When the capacitor is placed into the shell, it sits in this cup formed in the potting. In many instances, less than one-half of the thickness of the capacitor receives solder in the subsequent reflow operation (Figure 21). While this condition caused no failures in electrical or environmental testing, we feel that this condition would need to be eliminated if further development proceeds with CDI.

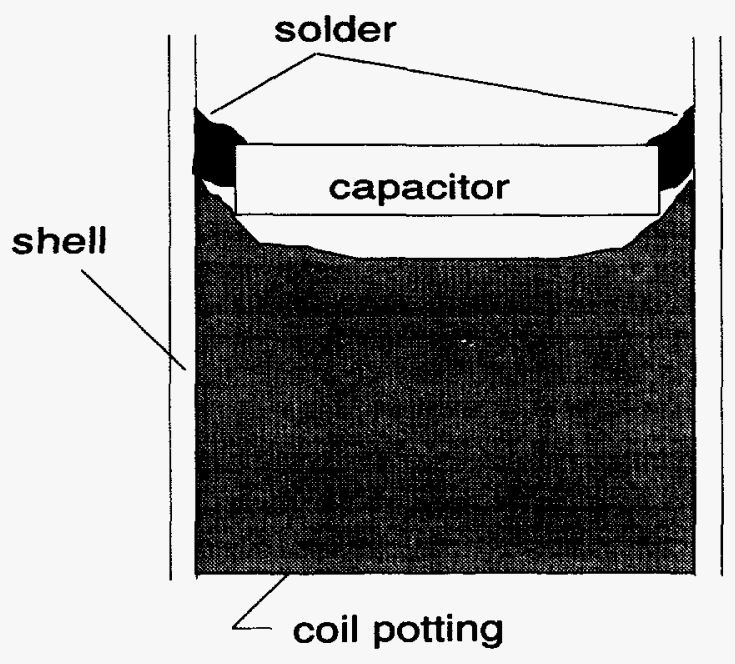

Figure 21. Capacitor Location in Shell.

SFE (Coil Disconnect). Because electrical tests were not conducted after each step of the environmental stress regimen, the particular stress causing the failure cannot be conclusively identified. However, the vibration stress, which is applied for over 2 hours, is a likely suspect. Following the combined environmental stresses, many of the filters displayed a lack of continuity from terminal to terminal, and a rattling sound was audible when filters were shaken. Examination of internal parts revealed the existence of loose coils between the capacitors with one or both of the coil wires severed. The tape that covers the coils displayed marks that probably came from rubbing against the inside of the case during vibration. Coils from filters not exposed to the environmental stresses did not display those marks. 
Spectrum Control (Capacitance Reduction). As discussed in the Thermal Cycling portion of the Test Results section, one of the capacitors inside of a Spectrum Control filter dropped to $15 \mathrm{nfd}$. Sandia's Glass and Electronic Ceramics Department also analyzed this capacitor. The cross section showed disconnection of some of the internal printed metalization (capacitor plates) and the termination at the discoidal I.D. The root cause is some inadequacy in the coating or firing process, which left the capacitor with weak bonds at those junctions.

Sierra Aerospace (Capacitance Reduction). The capacitance of one filter dropped to one-half of its original value after 150 thermal cycles. The condition persisted in all subsequent measurements. Impedance measurements made from either end of the filter enabled us to predict that the output capacitor (nonthreaded end) was no longer in the circuit. Destructive physical analysis and information published by Sierra Aerospace explain unique internal parts and assembly processes. While other manufacturers connect the coil wire to the discoidal capacitor by soldering the wire to the small metalized hole at the center of the capacitor, Sierra solders a metal tube (tubelet) to the center hole of the disoidal and passes the coil wire through the tubelet. The tubelet with the coil wire inside is fed through the terminal (also a metal tube) as the end caps are installed. After the end cap is secured, the tubelet, which is initially excessively long, is broken off by the assembler by wiggling it from side to side. The tubelet is designed to break off at the point of egress from the terminal tube. After trimming the coil wire and wrapping it around the terminal, the final operation is to seal the terminal with solder, which simultaneously connects the coil wire to the capacitor.

The filter that failed during thermal cycling was opened from the output end by pealing away the shell.
Pulling away the glass seal and terminal (combination intact) from the remainder of the assembly broke the coil wire at the point where it emerged from the terminal (inside the filter). The tubelet connected to the I.D. of the capacitor separated from the terminal with no evidence of previous connection (solder joint) at that end. Further examination of the inside of the terminal tubulation also revealed no remnant of the tubelet. The tubelet remained soldered to the capacitor. Similar disassembly of additional filters consistently left a large portion of the tubelet firmly soldered into, and protruding from, the terminal. Without exception, the tubelet broke into two pieces with one piece soldered into the terminal and the other piece remaining attached (by solder) to the capacitor.

We concluded that on the failed unit, the electrical connection of the capacitor to the coil and terminal was initially through physical contact only. We speculate that, at the time of assembly, the tubelet broke off inside the filter instead of where it emerges from the terminal (outside the filter). The subsequent soldering operation, which connected the coil wire to the terminal and sealed the filter, failed to reach the tubelet, which was shorter than its intended length.

\section{Summary}

We conclude that the Mil-F-28861/5 family of filters performs adequately to form a basis for developing SA replacements for the MC family of filters no longer available. However, tests will have to be added to the manufacturing process to ensure reliability and compliance to our specifications. We will judge the suppliers based on the performance of filters in this study and expect to conduct similar evaluations on filters built to our specifications by the most promising suppliers. 


\section{DISTRIBUTION:}

$7 \quad$ Allied Signal/Kansas City Division

Attn: A. L. Williams, S0C4, D416

S. M. Vaughn, 2D30, D452

D. L. Cheray, F038, D454

J. W. Brindley, D848-2, 2D39

C. U. Fotopoulos, D848-2, 22D39

R. A. Warren, D848-2, 2D39

J. D. Grauberger, D864, 2B37
MS 0525
S. E. Grieco, 2252
MS 0525
MS 0525
MS 0525
MS 0537
MS 0503
MS 0519
MS 0519
MS 0519
MS 0987
MS 0987
MS 0319
MS 0319
MS 0319
MS 0415
MS 0415
MS 0427
MS 0447
J. E. Lyons, 2252
P. V. Plunkett, 2252
R. Saavedra, 2252
D. D. Huffman, 2314
J. T. Love, 2337
D. A. Branscombe, 2612
C. M. Jenkins, 2612
K. H. Smith, 2612
J. W. Hole, 2631
K. B. Kimball, 2631
S. B. Martin, 2641
E. L. Smith, 2641
W. R. Nance, 2641
A. J. Grinley, 4111
D. M. Kunsman, 4111
V. O. Willan, 5103
P. D. Hoover, 5111

1

1

1

1

1

1

1

1

1

1

1

1

1

1

1

1

1

1
MS 0453

MS 0453

MS 0447

MS 0447

MS 0487

MS 0487

MS 0487

MS 0486

MS 0486

MS 0486

MS 0486

MS 0485

MS 0485

MS 0485

MS 0436

MS 0436

MS 9034

MS 9202

MS 9106

MS 0638

MS 0830

MS 9018

MS 0899

MS 0619

MS 0100
R. E. Kreutzfeld, 5111

R. C. Prew, 5111

T. Rohwer, 5111

F. J. York, 5111

J. D. Mangum, 5121

G. J. Bloom, 5121

T. A. Denman, 5121

W. D. Chadwick, 5122

W. H. Dodson, 5122

J. Morreale, 5122

B. Stiefeld, 5122

M. E. Bleck, 5123

J. W. Bonahoom, 5123

J. F. McDowell, 5123

G. L. Maxam, 5147

K. J. Payne, 5147

R. A. Van Cleave, 5363

L. E. Dighton, 8116

J. L. Van De Vreugde, 8417

L. Rieger, 12326

M. Newman, 12335

Central Technical Files, 8523-2

Technical Library, 13414

Technical Publications, 13416

Document Processing

for DOE/OSTI, 7613-2 